
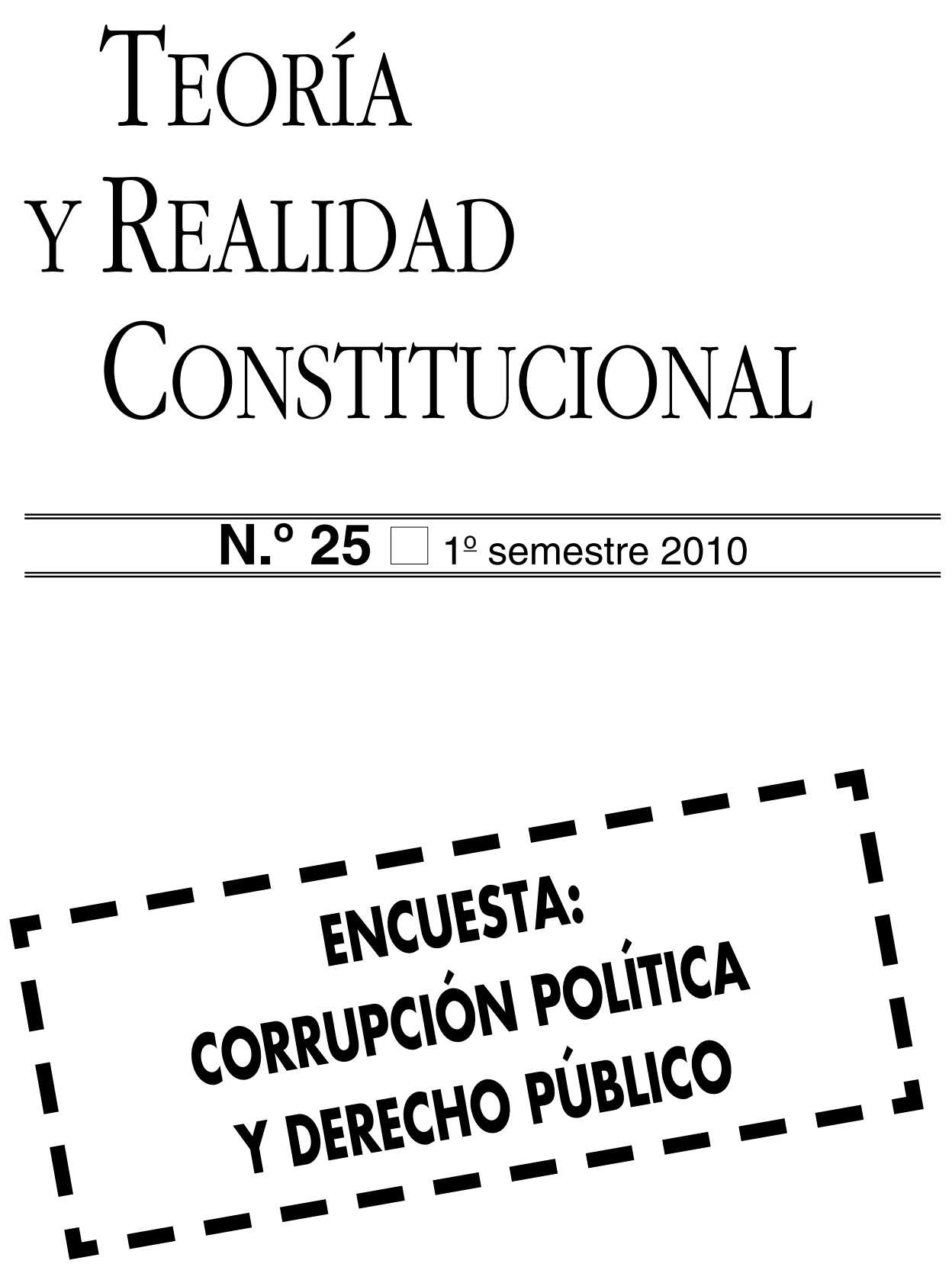


\title{
LA NUEVA CONSTITUCIÓN DE LA UNIÓN EUROPEA: EL TRATADO DE LISBOA Y LA REFORMA DE LOS TRATADOS CONSTITUTIVOS
}

\author{
ANTONIO BAR CENDÓN \\ Catedrático de Derecho Constitucional \\ Universidad de Valencia ${ }^{1}$
}

\author{
SUMARIO \\ I. Introducción: el cambio y su significado. \\ II. La nueva estructura constitucional de la \\ UE. \\ III. La reforma de los tratados. \\ IV. Conclusión.
}

\section{INTRODUCCIÓN: EL CAMBIO Y SU SIGNIFICADO}

La entrada en vigor, el 1 de diciembre de 2009, del Tratado de Lisboa ha supuesto la superación de una de las etapas más largas y tensas de la historia de la Unión Europea (en adelante: UE). Una etapa que estuvo caracterizada por el surgimiento de grandes expectativas con respecto al cambio en la estructura y en los contenidos sustantivos de la UE y por el frustrante fracaso de las mismas. Una larga etapa, en fin, cargada de incertidumbre sobre el futuro de la UE, que trajo consigo, como consecuencia lógica, una ralentización general del proceso de desarrollo de la Unión y una disminución considerable del peso de su influencia en el contexto internacional $-\mathrm{y}$, aún, en el interno- . Y esto ocurrió precisamente en un momento histórico en el que ese mayor peso e influencia de la UE y su capacidad para adoptar decisiones transcendentes eran — son- más necesarios y hubiesen sido decisivos en el decurso de los problemas más serios que hoy afrontamos todos: la crisis económica, el cambio climático, el terrorismo internacional, la amenaza nu-

1 Catedrático Jean Monnet de Derecho Constitucional de la UE. 
clear y los conflictos regionales enquistados, en Asia, Oriente Medio y África. En realidad, más que de una superación, en sentido propio, deberíamos hablar del fin de un ciclo y del inicio de una nueva etapa. Una nueva etapa que, deseablemente, debería conducirnos a la superación verdadera de los problemas que se plantearon entonces y que el Tratado de Lisboa pretende resolver en términos jurídico-formales, pero que, en términos políticos y prácticos, se necesitará aún un cierto tiempo para saber si la solución adoptada en Lisboa es verdaderamente la que la Unión necesitaba entonces y necesita ahora.

El Tratado de Lisboa, adoptado y firmado en esa ciudad por los Jefes de Estado o de Gobierno de la Unión Europea, el 13 de diciembre de $2007,{ }^{2}$ no fue el resultado de un proyecto novedoso de cambio que tratase de dar a la UE un nuevo impulso y que aportase, al mismo tiempo, soluciones satisfactorias a las largamente sentidas demandas de democratización, transparencia, apertura, simplificación y acercamiento a los ciudadanos europeos. Fue, más bien al contrario, el plan "B", la solución de mínimos imprescindible para superar la crisis creada por el fracaso del Tratado por el que se establece una Constitución para Europa. ${ }^{3}$ En realidad, era precisamente la fenecida Constitución europea la que trataba de aportar ese nuevo proyecto de Unión y de dar respuesta a esas demandas, que la misma UE había reconocido de manera oficial en la "Declaración relativa al futuro de la Unión" adoptada por el Consejo Europeo de Niza, de 7, 8 y 9 de diciembre del año 2000, y en la "Declaración sobre el Futuro de la Unión Europea - Declaración de Laeken", adoptada por el Consejo Europeo de Laeken, de 14 y 15 de diciembre de 2001. Así, la Declaración relativa al futuro de la Unión, de Niza, decía entonces:

"La Conferencia [...] reconoce la necesidad de mejorar y supervisar permanentemente la legitimidad democrática y la transparencia de la Unión y de sus instituciones, con el fin de aproximar éstas a los ciudadanos de los Estados miembros. ${ }^{4}$

Y, en la misma línea, la Declaración de Laeken entendía que la Unión debía afrontar simultáneamente un doble reto, uno dentro y otro fuera de sus fronteras. Así, decía:

2 Tratado de Lisboa por el que se modifican el Tratado de la Unión Europea y el Tratado constitutivo de la Comunidad Europea, firmado en Lisboa el 13 de diciembre de 2007 (Diario Oficial de la Unión Europea [en adelante: DO] C 306, 17.12.2007), y Acta de corrección de errores del Tratado de Lisboa por el que se modifican el Tratado de la Unión Europea y el Tratado constitutivo de la Comunidad Europea, firmado en Lisboa el 13 de diciembre de 2007 (DO C 290, 30.11.2009).

3 Tratado por el que se establece una Constitución para Europa (DO C 310, 16.12.2004); en adelante: Constitución europea, o Tratado constitucional.

4 Tratado de Niza por el que se modifican el Tratado de la Unión Europea, los Tratados constitutivos de las Comunidades Europeas y determinados actos conexos (2001/C 80/01). Declaraciones adoptadas por la Conferencia: 23. Declaración relativa al futuro de la Unión (DO C 80, 10.3.2001, pp. 85-86) 
"Dentro de la Unión, es preciso aproximar las Instituciones europeas al ciudadano. [...] Desean unas Instituciones europeas menos lentas y rígidas y, sobre todo, más eficientes y transparentes. [...] desea un papel más importante de la Unión en asuntos de justicia y seguridad, de lucha contra la delincuencia transfronteriza, control de las corrientes migratorias, acogida a los solicitantes de asilo y a los refugiados de zonas de conflicto periféricas. También pide resultados en el ámbito del empleo y la lucha contra la pobreza y la exclusión social, así como en el ámbito de la cohesión económica y social. Exige un enfoque común con respecto a la contaminación, el cambio climático y la seguridad de la alimentación. En resumen, un conjunto de asuntos transfronterizos para los que, de modo instintivo, siente que sólo pueden superarse mediante la cooperación. Del mismo modo, también desea más Europa en los asuntos exteriores, de seguridad y de defensa; con otras palabras, más acción y mejor coordinada a la hora de luchar contra los focos de conflicto en Europa, a su alrededor y en el resto del mundo.

Con otras palabras, lo que el ciudadano entiende por la «buena gestión de los asuntos públicos" es la creación de nuevas oportunidades, no nuevas rigideces. [...] En resumen, el ciudadano pide un enfoque comunitario claro, transparente, eficaz y conducido democráticamente, con el que Europa pueda dar una orientación al futuro del mundo. Un enfoque que consiga resultados concretos en términos de más empleo, mayor calidad de vida, menos delincuencia, una educación de calidad y mejores servicios sanitarios. Para ello, Europa debe indudablemente buscar renovadas fuentes de inspiración y reformarse. ${ }^{5}$

Muy en concreto, la Declaración de Niza proponía que el debate sobre el futuro de la Unión se centrase en cuatro puntos principales: a) la delimitación más precisa de las competencias entre la UE y los Estados miembros; $b$ ) el estatuto de la Carta de los Derechos Fundamentales de la Unión Europea; c) la simplificación de los Tratados con el fin de clarificarlos y facilitar su comprensión, sin cambiar su significado; y d) la función de los Parlamentos nacionales en la arquitectura europea. A lo que la Declaración de Laeken, modificando ligeramente la agenda diseñada en Niza, añadía: $a$ ) un mejor reparto y definición de las competencias de la Unión; b) la simplificación de sus instrumentos normativos; $c$ ) dotar de más democracia, transparencia y eficiencia a las instituciones; y, como consecuencia de todo ello, d) la adopción de un texto constitucional que aportase la reorganización, la simplificación, la transparencia y la eficiencia necesarias. Para todo lo cual, la Declaración de Laeken proponía la convocatoria de una Convención que debería abordar estas cuestiones y formular soluciones concretas a las mismas.

Este era, pues, el plan de entonces: más Europa, más unida, más simple, más cercana y accesible, más transparente y más eficaz, y, como consecuencia, con mayor peso en el mundo. Y a estos retos pretendió responder la fe-

5 Consejo Europeo de Laeken, de 14 y 15 de diciembre de 2001, Conclusiones de la Presidencia, Anexo I: Declaración de Laeken sobre el futuro de la Unión Europea. 
necida Constitución europea, nacida de la Convención propuesta en la Declaración de Laeken y de la Conferencia Intergubernamental (en adelante: CIG) que le siguió. Y la verdad es que el fenecido texto constitucional, si bien no puede decirse que hubiese logrado dar plena satisfacción a las demandas existentes y a las expectativas entonces creadas, sí, cuando menos, había logrado poner cierto orden, simplicidad, lógica y claridad en el complejo y disperso ordenamiento jurídico de la Unión. Y si esto es - fue- así, es muy difícil que el plan "B" —el Tratado de Lisboa_, la alternativa cercenada al fracasado proyecto constitucional, elaborada precisamente porque —al entender de algunos - aquél proyecto había ido más allá de lo debido en la consecución de los objetivos trazados, pueda ahora dar plena satisfacción a las demandas y necesidades de la UE en el contexto presente.

En esta línea, hay algo ya que, efectivamente - como veremos con detalle en las páginas que siguen-, el Tratado de Lisboa no consigue y, lo que es peor, no lo consigue de manera intencionada, por voluntad explícita de los Gobiernos de los Estados miembros: la claridad, la transparencia y la simplificación que se buscaban en los programas de Niza y de Laeken. Y faltó -y falta- claridad, transparencia y simplificación porque el objetivo político de los Gobiernos de los Estados fue precisamente difuminar y diluir el proceso de cambio que se iba a realizar — sustituir la fenecida Constitución europea por una reforma ordinaria de los Tratados- y hacerlo de tal manera que, no sólo quedase claramente manifiesto que lo que se hacía era una mera reforma de los Tratados — no su sustitución-, sino que fuese lo menos evidente posible que el contenido material de esa reforma, que lo que se introducía en los Tratados era precisamente el contenido sustancial de la Constitución europea. ${ }^{6}$

6 La decisión inicial de los Gobiernos de los Estados — nunca escrita— fue no publicar una edición oficial de los Tratados ya reformados según las previsiones del Tratado de Lisboa hasta que se hubiese completado el proceso de ratificación, cuando menos, en el Reino Unido, para no dar más motivos a los sectores contrarios a la reforma. Ello llevó a que varios de los Parlamentos nacionales de los Estados miembros ratificasen el Tratado de Lisboa sin tener una idea muy clara de cómo iban a quedar los Tratados después de esa reforma que tenían que aprobar. En algunos Estados, sin embargo, se realizaron ediciones particulares de los Tratados ya reformados de acuerdo con las previsiones del Tratado de Lisboa; así, en Francia (Assemblée Nationale, Treizième Législature, $\mathrm{N}^{\circ} 439$, Rapport d'information déposé en application de l'article 145 du Règlement par la Commission des Affaires Étrangères, sur les modifications apportées par le traité de Lisbonne au traité sur l'Union européenne et au traité instituant la Communauté européenne, Enregistré à la Présidence de l'Assemblée nationale le 28 novembre 2007) y en el Reino Unido (Consolidated Texts of the EU Treaties as Amended by the Treaty of Lisbon, Presented to Parliament by the Secretary of State for Foreign and Commonwealth Affairs, by Command of Her Majesty, January 2008). A esta labor se entregaron también otras entidades, como la Fundation for EU Democracy (Consolidated Reader-Friendly Edition of the Treaty on European Union (TEU) and the Treaty on the Functioning of the European Union (TFEU) as amended by the Treaty of Lisbon (2007), April 2008), o el Instituto Elcano, en España (obra realizada por José Martín y Pérez de Nanclares y Mariola Urrea Corres, el 26 de octubre de 2007), y la realizada por quien suscribe estas líneas, en diciembre de 2007. Finalmente, publicados ya los Tratados reformados por el propio Gobierno británico, el Consejo decidió publicar su versión oficial de los Tratados reformados 
Así, el Consejo Europeo de 21-22 de junio de 2007, que trató de cerrar de manera definitiva el fracasado proceso constitucional de la UE, lo hizo convocando una nueva Conferencia intergubernamental para que redactase un nuevo texto de reforma de los Tratados, dándole al mismo tiempo un mandato muy explícito y detallado, que fue ya el primer borrador de lo que luego sería, primero, el "Tratado de Reforma", y, finalmente, el "Tratado de Lisboa". Lo que debe ser destacado aquí es que el mandato del Consejo Europeo de junio de 2007 fue muy claro y contundente con respecto al proceso seguido hasta entonces y con respecto a lo que debería seguir en el futuro: los Tratados reformados "no tendrán carácter constitucional" - se dijo- y "no se utilizará el término 'Constitución'. Así, a lo largo de todo el texto del mandato no se utiliza ni una sola vez los términos "Tratado por el que se establece una Constitución para Europa" — nombre oficial de la frustrada Constitución europea-, ni siquiera "Tratado constitucional"; términos que habían sido profusamente utilizados en todos los documentos oficiales anteriores de este proceso incluido - lo que es muy llamativo- el Tratado de adhesión de Bulgasria y Rumanía. ${ }^{7}$ Ahora, la fenecida Constitución europea aparece referida de manera críptica como "las novedades resultantes de la CIG de 2004", "los términos acordados en la CIG de 2004", o las "innovaciones acordadas en la CIG de 2004 ".. ${ }^{8}$ La palabra "Constitución", pues, se convierte de nuevo en un término tabú, innombrable en la UE, como lo fue durante mucho tiempo antes, hasta el año 2000.

El Tratado de Lisboa, pues, supone un importante cambio en la estrategia de reforma de la UE iniciada en el año 2000 y el abandono del denominado "método constitucional", para volver al tradicional mecanismo de reforma de

— consolidados- de acuerdo con el Tratado de Lisboa, que vio la luz el 30 de abril de 2008, cuatro meses después de la firma del Tratado de Lisboa y cuando los Parlamentos de once Estados miembros lo habían ratificado ya (Hungría, Eslovenia, Malta, Rumanía, Francia, Bulgaria, Polonia, Eslovaquia, Portugal, Austria y Dinamarca). La versión final de los Tratados consolidados fue publicada en el Diario Oficial de la Unión Europea el 9 de mayo (C 115, 9.5.2008). En España, la ratificación se produjo con posterioridad a esa fecha, lo que, potencialmente, permitió al Congreso y al Senado conocer el resultado final de la reforma producida por el Tratado de Lisboa. La ratificación se realizó por la Ley Orgánica 1/2008, de 30 de julio, por la que se autoriza la ratificación por España del Tratado de Lisboa, por el que se modifican el Tratado de la Unión Europea y el Tratado Constitutivo de la Comunidad Europea, firmado en la capital portuguesa el 13 de diciembre de 2007 (BOE, 184, de 31.7.2008), y el depósito del instrumento español de ratificación tuvo lugar el 8 de octubre de 2008

7 El Ttratado de adhesión de 25 de abril de 2005, y el Prrotocolo correspondiente utilizan como referencia normativa de la Unión el Tratado por el que se establece una Constitución para Europa, que no era aún una norma jurídica vigente y que nunca llegó a serlo. Vid. DO L 157, 21.6.2005.

8 Vid. Conclusiones de la Presidencia. Consejo Europeo de Bruselas, 21 y 22 de junio de 2007 (11177/1/07 REV 1, CONCL 2), pp. 15-30. En realidad, las referencias a la "CIG 2004" son incorrectas, dado que la CIG que aprobó la Constitución europea se inauguró en Roma, el 4 de octubre de 2003, y se concluyó coincidiendo con el Consejo Europeo de Bruselas, de 17 y 18 de junio de 2004. El mandato del Consejo Europeo de junio de 2007 debería haberse referido, por tanto, a la "CIG 2003-2004". 
los Tratados. En otras palabras, los Tratados constitutivos de las Comunidades Europeas - en realidad, el Tratado de la Comunidad Europea y el Tratado de la Unión Europea- no van a ser sustituidos por un nuevo Tratado, formulado a través de un procedimiento peculiar - que incluyó la convocatoria de una Convención Europea y la celebración de cuatro referéndums, además de la obligada Conferencia Intergubernamental-, sino que van a ser modificados a través del procedimiento formal de reforma que preveía el Art. 48 del Tratado de la Unión Europea.

Así, el Tratado de Lisboa viene a reformar el Tratado de la Unión Europea, cuya denominación mantiene (en adelante: TUE), y el Tratado constitutivo de la Comunidad Europea, cuya denominación es cambiada y pasa a ser ahora "Tratado de Funcionamiento de la Unión Europea" (en adelante: TFUE), introduciendo en los mismos las modificaciones y novedades que habían sido previstas en la Constitución europea, a las que se añaden, además, algunas previsiones nuevas y algunas reformas de las mismas novedades que había pretendido introducir la Constitución europea. El fracaso del Tratado constitucional, pues, no ha supuesto una pérdida del conjunto de sus previsiones normativas, ni el abandono total de la trayectoria evolutiva de la UE hacia una, cada vez mayor y más intensa, integración política, ni siquiera ha excluido la conformación de la estructura jurídico-política de la Unión como una estructura de carácter constitucional, en la que se incluyen -aunque no en un código único, y con un ámbito competencial limitado- los elementos sustantivos de toda constitución política.

En este sentido, por un lado, el actual Art. 1 del TUE mantiene el texto del viejo Tratado, en el que se establece con claridad que "El presente Tratado constituye una nueva etapa en el proceso creador de una unión cada vez más estrecha entre los pueblos de Europa, en la cual las decisiones serán tomadas de la forma más abierta y próxima a los ciudadanos que sea posible". Es evidente, pues, que el proceso europeo de integración no puede ser considerado como definitivamente cerrado - muy a pesar del renaciente nacionalismo dominante en algunos Estados miembros- y que, por tanto, son esperables y deseables nuevos avances en la unión cada vez más estrecha entre los pueblos de Europa, tal y como reza el mencionado precepto.

Y, por otro lado, en lo que se refiere a la nueva estructura constitucional de la UE, es evidente también que ésta incluye los elementos sustantivos que permiten hablar de la existencia de una constitución política. Así, los nuevos Tratados resultantes del Tratado de Lisboa incluyen: $a$ ) una parte dogmática, compuesta por un conjunto de valores y principios superiores, así como los fines u objetivos que definen la Unión (previstos en el TUE), y una Carta de

9 El mandato del Consejo Europeo de junio de 2007 lo denominaba en castellano - de forma más correcta - "Tratado sobre el Funcionamiento de la Unión"; Su título verdadero, sin embargo, dado su contenido material, en el que sólo una pequeña parte - apenas cien artículos, sobre un total de 358 - se ocupa del funcionamiento de la Unión, debería haber sido "Tratado sobre las competencias de la Unión". 
Derechos Fundamentales, que es regulada de manera separada de los Tratados, pero que tiene el mismo valor jurídico que éstos, tal y como establece de manera explícita el Art. 6 del TUE; $b$ ) una parte orgánica, con detallada descripción de las instituciones de la Unión, de sus competencias y funcionamiento, así como y de las relaciones entre ellas (fundamentalmente en el TUE); c) un sistema de fuentes del Derecho, con una detalla descripción de las mismas y de su valor jurídico, cuyos destinatarios son tanto los Estados como los ciudadanos de la Unión (en el TFUE); $d$ ) un orden judicial, con detallada descripción de su estructura y del sistema de recursos procesales sustanciables a través del mismo y para cuya activación están legitimados tanto los Estados como los ciudadanos de la Unión (en el TUE y, principalmente, en el TFUE); y e) una parte competencial, propia de la naturaleza supranacional, cuasi federal, de la Unión, en la que se describe el ámbito material y las diferentes categorías de las competencias de la misma - competencias exclusivas, competencias compartidas con los Estados miembros, competencias de coordinación, competencias de apoyo y complemento de la acción de los Estados, y competencia en política exterior, de seguridad y de defensa- y se asientan los principios que rigen el sistema competencial: principios de atribución, de subsidiariedad y de proporcionalidad, así como los principios de respeto mutuo, de cooperación leal y de solidaridad; y, consiguientemente, el carácter "residual" de la competencia de los Estados: "Toda competencia no atribuida a la Unión en los Tratados corresponde a los Estados miembros", dicen los Arts. 4.1 y 5.2 del TUE (todo ello en el TUE y, con más detalle y extensión, en el TFUE).

No es la intención de este trabajo el describir en detalle el prolijo proceso de reforma que se inicia con el nacimiento de la Unión Europea, en 1993, ni siquiera de la fase "constituyente" del proceso, que parte de la Declaración de Laeken, de diciembre de 2001, y que se culmina con la entrada en vigor del Tratado de Lisboa, el 1 de diciembre de 2009; proceso cuyas raíces se hunden en los años ochenta del siglo XX, cuando se germina lo que luego habrá de ser la Unión Europea. Tampoco vamos a ocuparnos del atormentado proceso de ratificación que hubo de seguir el Tratado de Lisboa desde su firma, el 13 de diciembre de 2007, hasta su entrada en vigor dos años después, el 1 de diciembre de 2009; entrada en vigor que estuvo en cuestión hasta sólo unos días antes de esa fecha, pendiente de la ratificación por parte del último Estado en hacerlo: la República Checa, el 13 de noviembre de 2009. De todo ello nos hemos ocupado ya en otros lugares..$^{10} \mathrm{La}$ intención es concentrarnos aquí sólo en la descripción y análisis de la estructura constitucional mencionada y de las reformas del Tratado de Lisboa

10 Vid. A. BAR CENDÓN, «El Tratado de Lisboa y la reforma constitucional de la Unión Europea", Cuadernos Constitucionales de la Cátedra Fadrique Furió Ceriol, no 60/61 (2007) (de facto 2009), pp. 183-220, y "De Niza a Lisboa: El Tratado de Lisboa y la Carta de los Derechos Fundamentales de la UE", en A. BAR CENDÓN, Los Tratados de la Unión Europea. Edición anotada realizada por Antonio Bar Cendón (Valencia: Tirant lo Blanch, 2010). 
que han llevado a la misma, tratando de poner un poco más de luz sobre el contenido y significado de las mismas, así como destacar la continuidad existente entre la gran mayoría de esas reformas y la fenecida Constitución europea, de la que parten.

\section{LA NUEVA ESTRUCTURA CONSTITUCIONAL DE LA UE}

La reforma introducida por el Tratado de Lisboa afecta a dos ámbitos perfectamente diferenciados: por un lado, lo que podemos denominar la estructura jurídico-política, o constitucional, de la Unión Europea y, por otro, el contenido interno de los Tratados —el Tratado de la Unión Europea (TUE) y el Tratado de Funcionamiento de la Unión Europea (TFUE) —, tanto en su orden sistemático, como en su contenido normativo.

En el primer sentido, la primera y principal consecuencia de la entrada en vigor del Tratado de Lisboa es la conversión de la Unión Europea, ya no en un mero espacio híbrido - como era inicialmente, tras el Tratado de Maastricht, compuesto por un ámbito de cooperación política, de carácter intergubernamental, y un ámbito de integración económica, política y social, de carácter supranacional-, sino en un espacio único, homogéneo, de carácter supranacional (en el que, sin embargo, como se verá más adelante, van a quedar aún, de manera residual, ciertos elementos de intergubernamentalismo, en lo que se refiere específicamente al gobierno de la política exterior y de seguridad común, y de la política de defensa). El ámbito de cooperación política, realizado entre Estados soberanos, que se comportaban como tales en la gestión de esta cooperación (el Consejo como espacio exclusivo de decisión; voto por unanimidad; instrumentos normativos y decisorios particulares; exclusión del control político parlamentario; exclusión del control jurisdiccional, etc.) se refería específicamente a la cooperación en política exterior y de seguridad común, así como a la incipiente política de defensa, y a la cooperación en justicia y asuntos de interior. Mientras que el ámbito de integración económica, política y social, de carácter supranacional, se componía - se compone- de Estados que han cedido parte de su soberanía a un conjunto institucional que va a adoptar decisiones por mayoría (mayoría cualificada), pero vinculantes para todos los Estados miembros, y que va a legislar con carácter supremo en los ámbitos económicos, políticos y sociales atribuidos a ese conjunto institucional — la Comunidad Europea y la Comunidad Europea de la Energía Atómica- por los mismos Estados, y en la medida de la intensidad de la atribución realizada en cada caso.

En este sentido, se podría decir —utilizando la vieja jerga del Derecho europeo— que la Unión "Se comunitariza". Es decir — como veremos más adelante en detalle-, se suprime la estructura de pilares establecida por el Tratado de Maastricht y tanto el denominado segundo pilar - la cooperación en política exterior y de seguridad común - como el tercer pilar — la coopera- 
ción en justicia y asuntos de interior - se integran y se diluyen en el pilar comunitario - formado por la Comunidad Europea y la Comunidad Europea de la Energía Atómica-; en realidad, en términos propios y específicos, se diluyen sólo en el seno de la vieja Comunidad Europea. En otras palabras, tal y como prevé el actual Art. 1 del TUE: "La Unión sustituirá y sucederá a la Comunidad Europea".

La nueva Unión Europea aparece así definida en el Art. 3 del TUE como un "espacio de libertad, seguridad y justicia sin fronteras interiores, en el que esté garantizada la libre circulación de personas", con un "mercado interior", y una "unión económica y monetaria cuya moneda es el euro". A lo que el Art. 5 del TUE añade que "En virtud del principio de atribución, la Unión actúa dentro de los limites de las competencias que le atribuyen los Estados miembros en los Tratados para lograr los objetivos que éstos determinan", de lo que se deriva que "toda competencia no atribuida a la Unión en los Tratados corresponde a los Estados miembros" (Arts. 4.1 y 5.2 del TUE).

\section{A) LA SEPARACIÓN DE LA CEEA}

Lo peculiar de esta nueva estructura jurídico-política de la UE, que se deriva del Tratado de Lisboa, es que, por un lado, separa de ella a la Comunidad Europea de la Energía Atómica (CEEA), que pasa a ser una comunidad independiente, formada, eso sí, por los mismos Estados que son miembros también de la UE y por las mismas instituciones (excepto el Comité de las Regiones y el Banco Central Europeo); las cuales, sin embargo tienen funciones diferentes, determinadas por la especificidad de esta Comunidad supranacional. Incluso, los ingresos y los gastos de la Comunidad Europea de la Energía Atómica, con excepción de los de la Agencia de Abastecimiento y de las empresas comunes, van a ser consignados en el presupuesto de la Unión.

El devenir de la CEEA ha sido algo muy debatido en los últimos años. Su contenido y, sobre todo, el espíritu que lo inspiró en los años cincuenta del siglo pasado, son algo que hoy no suscita ya el mismo consenso entre los Estados miembros. La Comunidad se había creado entonces como una opción decidida a favor de la energía atómica como fuente de progreso. ${ }^{11}$ Así, cuando se formuló la Constitución europea, a lo largo de los años 2002-2004 las opciones que entonces se proponían iban desde la total derogación del Tratado CEEA, hasta su mera adaptación formal a las previsiones del nuevo proyecto de Tratado constitucional, ${ }^{12}$ pasando por las propuestas de reforma

11 El preámbulo del Tratado CEEA decía que "la energía nuclear constituye un recurso esencial para el desarrollo y la renovación de la producción y el progreso de las acciones en favor de la paz, [...] fuente de grandes disponibilidades de energía y de una modernización de la tecnologia, asi como de otras muchas aplicaciones que contribuyan al bienestar de sus pueblos".

12 Propuesta del Praesidium de la Convención Europea, junio de 2003: Annex I: Protocol Amending the Euratom Treaty. Sin embargo, éste fue un tema que no llegó a ser discutido en el seno del plenario de la Convención. 
radical de su contenido, manteniendo también su existencia, ${ }^{13} \mathrm{o}$, incluso, la formulación de una nueva Acta que vendría a sustituir el Tratado CEEA por un nuevo documento normativo de nivel inferior, más reducido y referido sólo a aspectos de seguridad, investigación, etc. —propuesta de la Comisión Europea- ${ }^{14}$ La solución final adoptada fue la propuesta por el Praesidium de la Convención Europea, que supuso la formulación de un nuevo Protocolo, a añadir a la Constitución europea, por el cual, al mismo tiempo que se mantenía el Tratado CEEA y, por tanto, la Comunidad Europea de la Energía Atómica, como algo separado pero vinculado a la nueva Unión Europea, se introducían también modificaciones formales en este Tratado, a fin de adaptarlo al nuevo Tratado constitucional.

El Tratado de Lisboa, pues, no hace sino recoger el mencionado Protocolo $\mathrm{n}^{\circ} 36$ que acompañaba a la Constitución europea, que pasa ahora a ser el Protocolo $\mathrm{n}^{\circ}$ 2, anexo al Tratado de Lisboa, con algunas modificaciones menores y de terminología, ${ }^{15}$ en el que, en sustancia, se mantiene la CEEA con su contenido tradicional y se revisa la previa comunidad institucional con la Unión Europea y la competencia de las instituciones. Son ahora instituciones comunes a la UE y a la CEEA: el Parlamento Europeo, el Consejo Europeo, el Consejo, la Comisión, el Alto Representante de la Unión para Asuntos Exteriores y Política de Seguridad, el Tribunal de Justicia de la Unión Europea, el Tribunal Cuentas, y el Comité Económico y Social. ${ }^{16}$ Y es común también a ambas el presupuesto anual de la UE y el control de su ejecución, el estatuto de los funcionarios y el régimen lingüístico.

La Unión Europea, pues, se separa formalmente de la Comunidad Europea de la Energía Atómica y, como establece de forma explícita el párrafo tercero del Art. 1 del TUE, se fundamenta sólo en el Tratado de la Unión Europea (TUE) y en el Tratado de Funcionamiento de la Unión Europea (TFUE), a los que se atribuye el mismo valor jurídico.

\section{B) La integración de la Carta de los Derechos Fundamentales de la UE}

En sentido justamente contrario, la UE va a hacer suya la Carta de los Derechos Fundamentales de la Unión Europea (CDFUE), de la que se hace un

13 Vid. Contribution by Ms Marie Nagy, Ms Renée Wagner and Mr Neil MacCormick, alternate members of the Convention: "The Future of the Euratom Treaty in the Framework of the European Constitution" (The European Convention, Brussels, 18 February 2003, CONV 563/03, CONTRIB 250).

14 Additional Act to the Constitution No 2: Peaceful use of Atomic Energy (Brussels, 2002). Esta Acta acompañaba al proyecto constitucional formulado entonces por algunos miembros de la Comisión Europea, denominado despectivamente por el Presidente de la Convención Europea, Giscard d'Estaing, proyecto "Penélope", y que pretendía ser una alternativa al borrador de Tratado constitucional que formulaba entonces la propia Convención Europea.

15 Protocolo $\mathrm{n}^{\circ} 2$ por el que se modifica el Tratado Constitutivo de la Comunidad Europea de la Energía Atómica (DO C 306, 17.12.2007, p. 199).

16 La CEEA cuenta también con un Comité Científico y Técnico, de carácter consultivo, pero el Comité de las Regiones carece de competencia en este ámbito. 
reconocimiento explícito en el Art. 6 del TUE, en el cual se establece que "La Unión reconoce los derechos, libertades y principios enunciados en la Carta de los Derechos Fundamentales de la Unión Europea de 7 de diciembre de 2000, tal como fue adaptada el 12 de diciembre de 2007 en Estrasburgo", y se añade, además, que ésta "tendrá el mismo valor jurídico que los Tratados". Si bien se añade también, como toda limitación, que "Las disposiciones de la Carta no ampliarán en modo alguno las competencias de la Unión tal como se definen en los Tratados" y que "Los derechos, libertades y principios enunciados en la Carta se interpretarán con arreglo a las disposiciones generales del título VII de la Carta por las que se rige su interpretación y aplicación y teniendo debidamente en cuenta las explicaciones a que se hace referencia en la Carta, que indican las fuentes de dichas disposiciones".

A mayor abundamiento, "los derechos bumanos, incluidos los derechos de las personas pertenecientes a minorias", son considerados parte de los valores fundamentales de la Unión, por el Art. 2 del TUE, y, en esta medida, no sólo constituye una obligación de la UE y de sus Estados miembros - y su objeto principal- la promoción de estos valores (Arts. 3 y 4 del TUE y Art. 51.1 de la CDFUE), sino que únicamente podrán solicitar su ingreso en la UE aquellos Estados europeos que respeten estos valores y que se comprometan a promoverlos (Art. 49 TUE); previéndose, además, sanciones específicas -incluida la suspensión de determinados derechos derivados de los Tratadospara todo Estado miembro que viole de manera grave y persistente estos valores (Art. 7 TUE).

El Tratado de Lisboa, pues, no incluye la Carta de los Derechos Fundamentales de la UE en el seno de los Tratados - ni en el TUE, ni en el TFUE-, sin embargo, por virtud de la previsión mencionada del Art. 6 del TUE, va a considerarla como un elemento sustantivo más, componente inseparable de la estructura constitucional de la UE, junto con éstos y con el mismo valor jurídico que ellos.

El Art. 6 del TUE hace referencia al devenir histórico de la formulación de la Carta, desde su primera proclamación formal en Niza, el 7 de diciembre de 2000, hasta su adopción final el 12 de diciembre de 2007, en Estrasburgo. No es la intención de este trabajo el ocuparse de ese proceso de formulación y reforma de la Carta — de ello nos hemos ocupado en otro lugar-,${ }^{17}$ baste simplemente mencionar aquí el hecho de que la nueva versión de la Carta recoge en sustancia el contenido normativo y la redacción original de la Carta del año 2000, a la que se hicieron simplemente algunas correcciones de estilo y terminológicas — tanto en el preámbulo como en el articulado—,${ }^{18} \mathrm{y}$ a la que se

17 Vid. A. BAR CENDÓN, «El Tratado de Lisboa y la reforma constitucional de la Unión Europea", cit., y "De Niza a Lisboa: El Tratado de Lisboa y la Carta de los Derechos Fundamentales de la UE", cit.

18 Entre los cambios introducidos se encuentran modificaciones de estilo como, por ejemplo, sustituir "hombres y mujeres" por "mujeres y hombres" (Art 23), "menores" por "niños" (Art. 24), "elector y elegible" por "sufragio activo y pasivo" (Arts. 39, 40); además de incluir la mención específica a los nuevos Tratado de la Unión Europea y Tratado de Funcionamiento de la Unión Eu- 
añadieron, en el Art. 52, cuatro nuevos párrafos, conteniendo nuevos parámetros interpretativos de los derechos fundamentales contenidos en la Carta.

En su conjunto, la Carta de los Derechos Fundamentales de la Unión Europea es un extenso documento de 54 artículos, que - como el propio preámbulo de la Carta establece- supone una reafirmación de slos derechos que emanan, en particular, de las tradiciones constitucionales y las obligaciones internacionales comunes a los Estados miembros, del Convenio Europeo para la Protección de los Derechos Humanos y de las Libertades Fundamentales, las Cartas Sociales adoptadas por la Unión y por el Consejo de Europa, asi como de la jurisprudencia del Tribunal de Justicia de la Unión Europea y del Tribunal Europeo de Derechos Humanos". Y la intención —como expresa el mismo preámbulo, remedando lo dicho en el preámbulo de la declaración francesa de los derechos del hombre y del ciudadano, de 1789- es dar una mayor proyección y refuerzo de la protección de esos derechos fundamentales comunes mediante su publicación en esta Carta.

La verdad es, sin embargo, que no todos los derechos contenidos en la Carta, provienen de las tradiciones o de las previsiones constitucionales vigentes de los Estados miembros, ni siquiera del mencionado Convenio Europeo, sino que son formulaciones altamente novedosas, derivadas del presente estado de la evolución de la sociedad y de los avances científicos y tecnológicos, como dice la misma Carta. En este sentido — entre otros- pueden ser mencionados el respeto al "consentimiento libre e informado de la persona", en el marco de la medicina, así como la prohibición de las prácticas eugenésicas, de la clonación reproductora de seres humanos, o la prohibición de la utilización del cuerpo humano, o de partes del mismo, con fines lucrativos (Art. 3); el derecho a la protección de los datos de carácter personal (Art. 8); la libertad de empresa (Art. 16); la prohibición de las expulsiones colectivas (Art. 19); la posibilidad de la acción positiva, o "adopción de medidas que supongan ventajas concretas en favor del sexo menos representado" (Art. 23); el derecho de acceso a un servicio gratuito de colocación (Art. 29); el derecho a una ayuda social y a una ayuda de vivienda, de todos aquellos que no dispongan de recursos suficientes, con el fin de combatir la exclusión social (Art. 34); el derecho al acceso a los servicios de interés económico general (Art. 36); la protección del medio ambiente, conforme al principio de desarrollo sostenible (Art. 37); el derecho a una buena administración (Art. 41); y el derecho de acceso a los documentos de las instituciones, cualquiera que sea su soporte (Art. 42).

En todo caso, por un lado, la Carta tiene un ámbito jurisdiccional limitado —el ámbito propio de la aplicación del Derecho de la Unión- y no amplía el ámbito de aplicación de este Derecho más allá de las competencias y misiones de la UE definidas en los Tratados (Art. 6 TUE y Art. 51.2 CDFUE). En este sentido, pues, la Carta no pretende sustituir a los sistemas de protección de los derechos fundamentales de los Estados miembros, sino que, de manera

ropea (Arts.18; 21.2, 36), al "Derecho de la Unión", en vez del "Derecho comunitario" (Arts. 16, 27, 28, 30, 34), y a la "Unión", en vez de la "Comunidad" (Art. 41). 
paralela o complementaria, viene sólo a atribuir una garantía especial de esos derechos en los conflictos que puedan surgir en la aplicación del Derecho de la Unión, no del Derecho nacional. Y, por otro lado, en este mismo sentido, la Carta obliga sólo a las instituciones, órganos y organismos de la Unión, y a los Estados miembros únicamente cuando apliquen el Derecho de la Unión (Art. 51.1 CDFUE) ${ }^{19}$ En todo caso, como ya hemos visto en párrafos anteriores, los Estados y la Unión están obligados a respetar los derechos y a observar los principios de la Carta, así como a promover su aplicación, con arreglo a sus respectivas competencias (Art. 2 TUE y Art. 51.1 CDFUE). Así, se puede decir que, si bien el ámbito de jurisdicción de la Carta es sólo el Derecho de la UE y su aplicación, en cambio, su vigencia o aplicación es completa y no hay partes de la misma sometidas a restricción o atenuación normativa alguna.

La Carta, pues —dentro de ese ámbito específico-, es plenamente exigible, en la medida en que, como establece el Art. 6.1 del TUE, tiene el mismo valor jurídico que los Tratados. En este sentido, en lo que se refiere a los derechos fundamentales propiamente dichos, los actos vulneradores de los mismos realizados en aplicación del Derecho de la UE, pueden ser objeto de recurso de nulidad ante el TJUE, por "violación de los Tratados" (Art. 263 TFUE, en relación con Art. 6.1 TUE). Y, en lo que se refiere a las disposiciones de la Carta que contengan principios, éstas sólo podrán ser alegadas ante un juez en la medida en que sean aplicadas por actos legislativos y ejecutivos de las instituciones o de los Estados, cuando apliquen el Derecho de la Unión, y sólo en lo que se refiere al control de legalidad de dichos actos (Art. 52.5 CDFUE).

En fin, en lo que se refiere a la interpretación de la Carta, el Art. 52 de la misma establece, en sus cinco últimos párrafos, parámetros concretos de interpretación, entre los cuales deben ser destacadas aquí las denominadas Explicaciones sobre la Carta de los derechos fundamentales, a las que se refiere también el Art. 6.1 del TUE. ${ }^{20}$ Estas Explicaciones fueron elaboradas inicialmente por el Praesidium de la Convención que redactó la Carta, en los años 1999-2000, basándose en el Convenio Europeo para la Protección de los Derechos Humanos y de las Libertades Fundamentales, así como en los Protocolos de actualización y en la propia jurisprudencia del Tribunal de Estrasburgo; fueron después actualizadas por el Praesidium de la Convención que redactó la Constitución europea, y, finalmente, fueron retomadas y adaptadas

19 La Declaración ( $\mathrm{n}^{\circ}$ 1) relativa a la Carta de los Derechos Fundamentales de la Unión Europea, aneja al Acta Final de la Conferencia intergubernamental que adoptó el Tratado de Lisboa, no sólo reafirma que la Carta no amplía el ámbito de aplicación del Derecho de la Unión más allá de las competencias de la Unión, ni crea ninguna nueva competencia, sino que establece que la Carta confirma los derechos fundamentales garantizados por el Convenio Europeo para la Protección de los Derechos Humanos y de las Libertades Fundamentales — del que son signatarios todos los Estados miembros de la Unión- y tal como resultan de las tradiciones constitucionales comunes a los Estados miembros (DO C 306, 17.12.2007).

20 Vid. Explicaciones sobre la Carta de los Derechos Fundamentales (2007/C 303/02) (DO C 303, 14.12.2007, pp. 17-35). 
a las previsiones de la nueva Carta de 2007. Las Explicaciones carecen de valor jurídico y, como se establece en su propio preámbulo, son sólo un «alioso instrumento de interpretación con objeto de aclarar las disposiciones de la Carta. Sin embargo, lo peculiar de su posición jurídica es que, a pesar de lo dicho en su preámbulo, son puestas por el TUE y por la propia Carta, como parámetro de interpretación de los derechos contenidos en ésta, al lado de otros instrumentos jurídicos vinculantes —en pié de igualdad-, como el propio Convenio Europeo, en el que se inspiran, o las tradiciones constitucionales comunes a los Estados miembros. Y así lo establecen el Art. 6.1 del TUE, que prevé que los derechos, libertades y principios enunciados en la Carta se interpretarán "teniendo debidamente en cuenta las explicaciones a que se hace referencia en la Carta, que indican las fuentes de dichas disposiciones", y el Art 52.7 de la Carta, el cual añade, de manera más específica y contundente, que "Las explicaciones elaboradas para guiar en la interpretación de la presente Carta serán tenidas debidamente en cuenta por los órganos jurisdiccionales de la Unión y de los Estados miembros".

No cabe duda alguna, pues, con respecto a que la Carta es una parte inseparable de la nueva estructura constitucional de la UE, ni con respecto al valor jurídico o fuerza vinculante de la misma. El problema y las mayores dudas se plantean con respecto a su exigibilidad, en el momento de decidir cuándo nos encontramos verdaderamente ante la aplicación de Derecho europeo por parte de los Estados y, por tanto, a la hora de determinar la jurisdicción competente en la protección de derechos fundamentales que son comunes con los previstos en las Constituciones nacionales. Así, si bien es evidente que las instituciones de la Unión aplican sólo el Derecho europeo en todas sus actuaciones y, por lo tanto, quedan plenamente sujetas a las previsiones materiales de la Carta y a las previsiones procesales de los Tratados a la jurisdicción del Tribunal de Justicia de la UE-; en lo que se refiere a los Estados miembros la cuestión no está tan clara y el problema se plantea principalmente en ese ámbito, siempre mal definido, de la aplicación estatal del Derecho europeo. Ámbito en el que se incluye no sólo la aplicación de los reglamentos de la UE — que son claramente Derecho europeo-, sino también el desarrollo de las directivas y de otra normativa europea -actos, programas, etc.- por normas y actos de carácter estatal. Espacio en el que precisamente se produce el contacto más intenso e inmediato entre la administración y los ciudadanos y, por lo tanto, donde es más esperable la vulneración de derechos comprendidos en la Carta. ¿Dónde se encuentra aquí el límite del Derecho europeo y el del Derecho nacional? ¿cuándo actúan las autoridades nacionales en desarrollo de su propio orden jurídico, o cuándo operan como agencias ejecutivas del orden jurídico europeo? ¿cuál es, en definitiva, la jurisdicción competente en cada caso?

Este aspecto problemático de la Carta, pues, es algo que requiere una mayor clarificación y ello sólo puede venir dado por la experiencia y por la jurisprudencia que el Tribunal de Justicia de la UE vaya elaborando al respecto. 


\section{LA REFORMA DE LOS TRATADOS}

\section{A) El Tratado de Lisboa y los Tratados de la Unión}

En lo que hace referencia a la estructura y contenido de los Tratados como ya hemos visto en páginas anteriores-, el Tratado de Lisboa afecta de lleno a los tres Tratados constitutivos hasta entonces vigentes: el Tratado de la Unión Europea (TUE), que conserva su denominación, el Tratado de la Comunidad Europea, que pasa a ser denominado ahora Tratado de Funcionamiento de la Unión Europea (TFUE), y el Tratado de la Comunidad Europea de la Energía Atómica (TCEEA), que, si bien mantiene igualmente su denominación, es separado de la estructura que forma ahora la Unión Europea, aunque es adaptado también, principalmente en su dimensión institucional, a los nuevos cambios que el Tratado de Lisboa introduce en los otros dos Tratados que van a formar la Unión Europea.

En términos generales, puede decirse que el Tratado más afectado en su estructura, contenido y significado es el TUE. De sus seis Títulos, cuatro son enteramente nuevos (Tit. I: Disposiciones comunes, Arts. 1-8; Tit. II: Disposiciones sobre los principios democráticos, Arts. 9-12; Tit. III: Disposiciones sobre las instituciones, Arts. 13-19; y Tit. VI: Disposiciones finales, Arts. 47-55); y de sus 55 artículos (el viejo TUE tenía 53 artículos), 38 artículos (el 69\%) son de texto enteramente nuevo. Si a todo ello se añade también las modificaciones menores introducidas en el articulado — cambios en la terminología y las supresiones, añadidos o modificaciones menores en párrafos o frases-, cabría decir, en realidad que la totalidad del texto del TUE se ha visto afectada por la reforma.

Por otra parte, el TUE pasa a ser ahora el núcleo central de la estructura constitucional de la UE, y por eso precisamente ha sido el objeto principal de la reforma realizada por el Tratado de Lisboa. En el TUE se regulan ahora los valores y objetivos de la UE (Arts. 2-3); el régimen general de las competencias de la UE y de los Estados miembros (Arts. 4-5); el régimen general de los derechos fundamentales (Arts. 6-7); las disposiciones sobre los principios democráticos —igualdad, participación, papel de los Parlamentos nacionales- (Arts. 9-12); la regulación básica de las instituciones de la Unión (Arts. 13-19); las disposiciones generales relativas a la acción exterior de la Unión y las disposiciones específicas relativas a la política exterior y de seguridad común y a la política de defensa (Arts. 21-46); y, en fin, las disposiciones generales sobre las cooperaciones reforzadas (Art. 20), y las disposiciones finales sobre la personalidad jurídica de la Unión (Art. 47), el procedimientos de reforma de los Tratados (Art. 48), el procedimiento de admisión en la UE (Art. 49), y el procedimiento de salida de la UE (Art. 50), además de otras disposiciones.

El TFUE, en cambio — en lo sustancial—, pasa a ser el Tratado en el que se desarrollan y complementan buena parte de las previsiones del TUE. Por otra parte, la reforma operada en este Tratado no ha sido tan intensa como la 
que tuvo lugar en el TUE, dado que el TFUE - heredero del Tratado de la Comunidad Europea (TCE) - regula el conjunto de las políticas y competencias de la UE que ya figuraban en el TCE; terreno en el que la reforma producida por el Tratado de Lisboa no ha sido tan importante.

El TFUE pasa a tener ahora 358 artículos (el TCE tenía 314 artículos), de los cuales, sólo 113 (el 32\%) cuentan ahora con una redacción enteramente nueva. Si bien debemos decir aquí, una vez más, que, si a ello añadimos las modificaciones menores introducidas en el articulado — cambios en la terminología, supresiones, añadidos o modificaciones menores en párrafos o frases-, así como la reordenación o cambios de ubicación de determinados preceptos, cabría decir, en realidad, que la reforma ha afectado a más del 80\% del Tratado.

El TFUE se estructura ahora en siete partes (una más de las que tenía el TCE), de las cuales, tres permanecen sin cambio sustancial alguno, y cuatro de ellas han sido modificadas de manera importante: La Primera Parte: Principios (Arts. 1-17), donde se detallan las categorías y ámbitos de las competencias de la UE y otras disposiciones de aplicación general. La Segunda Parte: No discriminación y Ciudadanía de la UE (Arts. 18-25). La Quinta Parte: Acción exterior de la UE (Arts. 205-222), donde, además de las disposiciones generales relativas a la acción exterior de la UE (Art. 205), la cooperación con terceros países y la ayuda humanitaria (Arts. 208-214), los acuerdos internacionales (Arts. 216-219), las relaciones de la UE con las organizaciones internacionales y con terceros países (Arts. 220 - 221), se incluyen ahora también cosas un tanto heterogéneas, como la política comercial común (Arts. 206-207) y la cláusula general de solidaridad (Art. 222). Y la Sexta Parte: Disposiciones institucionales y financieras, donde se recoge el funcionamiento de las instituciones de la UE, las fuentes del Derecho y el régimen financiero de la Unión, y también se desarrollan las disposiciones referidas a las cooperaciones reforzadas (Arts. 223-334).

En conjunto, pues, como puede comprobarse por su contenido material, la denominación dada a este Tratado - Tratado de Funcionamiento de la Unión Europea - no responde de manera adecuada a su contenido normativo, dado que a penas cien de sus artículos (Arts. 223-325) puede decirse con propiedad que se refieren al funcionamiento de la Unión, mientras que los otros 258 artículos restantes se refieren más bien a describir las políticas y competencias de la UE.

Tanto el TUE como el TFUE, pues, se han visto afectados de manera sustantiva por la reforma realizada por el Tratado de Lisboa, que introduce en su seno el conjunto de las aportaciones novedosas que preveía la fenecida Constitución europea. En este sentido, como se ha visto, y si nos referimos exclusivamente a la introducción de preceptos enteramente nuevos puede decirse que la reforma introducida por el Tratado de Lisboa afecta a casi el setenta por cien del TUE y a algo más del treinta por cien del TFUE. Sin embargo, si tomamos el tema desde la perspectiva de la propia Constitución europea, podríamos decir que prácticamente la totalidad de la misma, con 
muy contadas excepciones, pasa al TUE y al TFUE, con lo que puede decirse que aquella fracasada reforma constitucional, después de todo, no se realizó en vano.

En las páginas que siguen se analiza en detalle precisamente el conjunto de las reformas producida por el Tratado de Lisboa y la medida en que éstas suponen una traslación a los Tratados de la Unión de las reformas que preveía la fenecida Constitución europea. Así, nos referimos en primer lugar, a las previsiones novedosas de la Constitución europea que el Tratado de Lisboa no recoge, y, después, a las reformas introducidas por el Tratado de Lisboa, provenientes —en la gran mayoría de los casos_-, o no, del fenecido Tratado constitucional. $^{21}$

\section{B) Previsiones de la Constitución Europea EXCluidas}

Las Previsiones de la Constitución europea que no son recogidas por el Tratado de Lisboa son pocas, si bien tienen un alto valor simbólico y son precisamente aquellos aspectos que dotaban al fenecido Tratado constitucional de su apariencia formal y simbólica de Constitución y que, por lo tanto, habían suscitado la particular animadversión de los sectores más nacionalistas o "euroescépticos", celosos de la soberanía de los Estados miembros y de la protección de sus símbolos identitarios. En su concepción, estos elementos que ahora se abandonan dotaban a la UE de una imagen indebida de super-Estado y, por ello, no podían pasar a los Tratados.

\section{- Abandono de la Constitución}

Se abandona tanto la forma como la denominación "Constitución", manteniéndose la tradicional de "Tratado". Así, el Art. 1 del TUE establece ahora que "La Unión se fundamenta en el presente Tratado y en el Tratado de Funcionamiento de la Unión Europea (en lo sucesivo denominados 'los Tratados').

\section{- Unión de Estados}

La UE ya no es definida como una unión de Estados y de ciudadanos, como lo hacía la Constitución europea ("nace de la voluntad de los ciudadanos y de los Estados de Europa" — decía el Art. I-1 de la Constitución europea), sino como una unión de Estados: "las Altas Partes Contratantes constituyen entre sí una Unión Europea ... a la que los Estados miembros atribuyen competencias para alcanzar sus objetivos comunes", dice ahora el Art. 1 del TUE.

$21 \mathrm{El}$ análisis que sigue recoge en parte lo dicho en el apartado final de mi trabajo "De Niza a Lisboa: El Tratado de Lisboa y la Carta de los Derechos Fundamentales de la UE", cit.; si bien el análisis que aquí se realiza es mucho más extenso y detallado. 
Es verdad, sin embargo, que a lo largo de su articulado, tanto el TUE como el TFUE, no conciben a la UE como una mera asociación internacional de Estados, en el sentido restringido, sino que la dotan de un contenido que transciende con mucho esa conceptuación y ponen al ciudadano en el centro de su acción, como sujeto del Derecho de la Unión — participación, ciudadanía, derechos fundamentales, etc.- En este sentido, por ejemplo, el Art. 10 del TUE, al describir el funcionamiento de la Unión, establece que éste se basa en la "democracia representativa", dentro de la cual, "Los ciudadanos estarán directamente representados en la Unión a través del Parlamento Europeo", mientras que los Estados miembros "estarán representados en el Consejo Europeo por su Jefe de Estado o de Gobierno y en el Consejo por sus Gobiernos".

\section{- Desconstitucionalización de los símbolos}

El Tratado de Lisboa abandona también la referencia a los símbolos de la UE (bandera, himno, divisa, día de Europa) que figuraban en el Art. I-8 de la Constitución europea y que no son incluidos en los Tratados. Se conserva, en cambio, la referencia al euro, que figura ahora mencionado en el apartado 4 del Art. 3 del TUE. ${ }^{22}$

\section{- Desconstitucionalización de la primacía del Derecho de la UE}

Se abandona la referencia a la primacía del Derecho de la UE sobre el Derecho de los Estados miembros, que figuraba en el Art. I-6 de la Constitución europea. Si bien, paradójicamente, y para compensar esta significativa cercenación, se adopta la Declaración ( $\mathrm{n}^{\circ} 17$ ) relativa a la primacía, que se incluye en el Acta final de la CIG 2007, en la cual se viene a decir que "La Conferencia recuerda que, con arreglo a una jurisprudencia reiterada del Tribunal de Justicia de la Unión Europea, los Tratados y el Derecho adoptado por la

22 Dieciséis Estados miembros, sin embargo, decidieron adoptar la Declaración (52) relativa a los símbolos de la Unión Europea, que se adjunta al Acta final de la Conferencia intergubernamental que adoptó el Tratado de Lisboa, de 13 de diciembre de 2007, en la que se establece que "Bélgica, Bulgaria, Alemania, Grecia, España, Italia, Chipre, Lituania, Luxemburgo, Hungría, Malta, Austria, Portugal, Rumanía, Eslovenia y Eslovaquia declaran que la bandera que representa un círculo de doce estrellas doradas sobre fondo azul, el himno tomado del "Himno a la Alegría" de la Novena Sinfonía de Ludwig van Beethoven, la divisa "Unidad en la diversidad", el euro en tanto que moneda de la Unión Europea y el Día de Europa el 9 de mayo seguirán siendo, para ellos, los símbolos de la pertenencia común de los ciudadanos a la Unión Europea y de su relación con ésta" (DO C 115, 9.5.2008, p. 355). Por otra parte, el 9 de octubre de 2008, el Parlamento Europeo adoptó una reforma de su Reglamento Interno, por la que, entre otras cosas, se establece —en su redacción actual— que "El Parlamento reconocerá y hará suyos los siguientes símbolos de la Unión: la bandera representando un círculo de doce estrellas doradas sobre fondo azul; el himno tomado del "Himno a la Alegría" de la Novena Sinfonía de Ludwig van Beethoven; la divisa "Unida en la diversidad", a lo que se añade también que "El Parlamento celebrará el Día de Europa el 9 de mayo" (Art. 213: Simbolos de la Unión, Parlamento Europeo, Reglamento, $7^{\mathrm{a}}$ legislatura, Diciembre 2009). 
Unión sobre la base de los mismos priman sobre el Derecho de los Estados miembros, en las condiciones establecidas por la citada jurisprudencia". ${ }^{23}$

- Separación de la Carta de los Derechos Fundamentales de la UE

La Carta de los Derechos Fundamentales de la UE - como ya hemos visto en páginas anteriores - no es incluida en los Tratados, si bien es mantenida como un texto aparte, jurídicamente vinculante. En este sentido, la Carta con algunas modificaciones sobre la versión original del año 2000- ha sido de nuevo proclamada solemnemente por el Parlamento Europeo, el Consejo y la Comisión, el 12 de diciembre de 2007, en Estrasburgo, y el Art. 6 del TUE le atribuye el mismo valor jurídico que los Tratados.

\section{- Mantenimiento de la denominación tradicional de los instrumentos jurídicos}

Uno de los aspectos importantes y necesarios de la reforma de la UE que tanto la Declaración de Niza, del año 2000, como la Declaración de Laeken, del año 2001, recogían como punto principal a abordar en este proceso de reforma, era la simplificación del ordenamiento jurídico de la Unión ( la simplificación de los Tratados con el fin de clarificarlos y facilitar su comprensión, sin cambiar su significado", decía, en términos muy amplios la Declaración de Niza; o "la simplificación de sus instrumentos normativos", decía, en términos más modestos, la Declaración de Laeken).

La Constitución europea, apoyándose en esta exigencia, realizó una reforma sistemática del ordenamiento jurídico de la Unión, llena de lógica jurídica, y, así, no sólo cambió la denominación, sino también la forma jurídica - procedimiento de elaboración, instancia reguladora, valor normativo- de los instrumentos normativos de la UE, introduciendo entre ellos, como consecuencia necesaria, la jerarquía normativa. Así, básicamente, la Constitución europea distinguía entre actos legislativos (la "ley europea" y la "ley marco europea"), adoptados conjuntamente por el Parlamento Europeo y el Consejo, por el procedimiento legislativo ordinario, o por procedimientos legislativos especiales; y los actos no legislativos, que eran, en realidad, todos los demás, adoptados por procedimientos no legislativos y por las instituciones indicadas en cada caso en la Constitución (el "reglamento europeo", la "decisión europea", las "recomendaciones", los "dictámenes", además del "reglamento europeo delegado", el "reglamento europeo de ejecución" y la "decisión europea de ejecución") (Arts. I-33 a I-37 del Tratado constitucional).

El Tratado de Lisboa, ante la exigencia de prescindir de todos aquellos aspectos de la Constitución europea que supusiesen un elemento definidor de un Estado soberano - en este caso, las denominaciones de "ley" y "reglamen- 
to", tal y como son concebidos en los Estados miembros-, decidió abandonar este aspecto de la reforma constitucional y mantener la terminología tradicional de "reglamento", "directiva", "decisión", "recomendación" y "dictamen" (antiguo Art. 249 del TCE), que pasa ahora a los Arts. 288-291 del TFUE. El Tratado de Lisboa, sin embargo, de manera incoherente, mantiene todas las previsiones de la Constitución europea referidas al contenido sustancial de los nuevos instrumentos normativos — forma, valor jurídico—, incluida la jerarquía normativa, que era una parte sistemática de aquella reforma. De esta manera, ahora vamos a encontrarnos, por ejemplo, con reglamentos, directivas y decisiones legislativas y, por tanto, de rango superior, junto con reglamentos, directivas y decisiones no legislativas y, por tanto, de rango inferior.

Todo ello, pues, lejos de atender a la demanda de clarificación y simplificación de las Declaraciones de Niza y de Laeken, no hace sino añadir más complejidad y obscuridad — tanto desde el punto de vista material, como desde el punto de vista formal y el terminológico- a un ordenamiento jurídico que era ya de por sí muy confuso y de difícil comprensión.

\section{- Abandono de la denominación "Ministro de Asuntos Exteriores de la Unión"}

La denominación "Ministro de Asuntos Exteriores de la Unión", empleada por el Tratado constitucional (Art. I-28), en la medida en que es más propia de una estructura gubernamental nacional y, además, en la medida en que también parece poner a esta figura por encima de los Ministros nacionales del ramo, es abandonada por el Tratado de Lisboa y sustituida por la de "Alto Representante de la Unión para Asuntos Exteriores y Politica de Seguridad", más cercana a la tradicionalmente utilizada para esta figura ("Secretario General del Consejo, Alto Representante de la Política Exterior y de Seguridad Común»: Art. 26 TCE). Se mantienen, sin embargo, todos los demás aspectos de la institución que estaban previstos en el Tratado constitucional (Art. 18 del TUE).

\section{C) Novedades introducidas por el Tratado de Lisboa}

Las grandes novedades introducidas en los Tratados por el Tratado de Lisboa provienen en su práctica totalidad de la fenecida Constitución europea. ${ }^{24}$ Estas novedades pueden ser agrupadas en dos grandes bloques: $a$ ) las

24 Véanse, a este respecto, el informe de RICHARD CORBETT e IÑIGO MÉNDEZ DE VIGO al Parlamento Europeo (Parlamento Europeo, Comisión de Asuntos Constitucionales, Informe sobre el Tratado de Lisboa. Ponentes: RICHARD CORBETT e ÍÑIGO MÉNDEZ DE VIGO (2007/2286(INI)) (A6-0013/2008), Bruselas, 29.1.2008), y la Resolución del Parlamento Europeo que se basa en el mismo (Resolución del Parlamento Europeo, de 20 de febrero de 2008, sobre el Tratado de Lisboa (2007/2286(INI), Estrasburgo, 20 de febrero de 2008). 
novedades que afectan a la estructura e instituciones de la Unión, y b) las novedades de carácter sustantivo o material, que afectan a su ámbito competencial y funcionamiento.

a) Reformas estructurales e institucionales

\section{- Supresión de la estructura de pilares}

Como hemos visto en páginas anteriores, una de las grandes y más radicales reformas introducidas por el Tratado de Lisboa es la supresión de la vieja estructuración de la UE en "pilares", que había sido establecida por el Tratado de Maastricht. El cambio se ha operado en una doble y contraria dirección. Por un lado, se ha separado a la vieja Comunidad Europea de la Energía Atómica del complejo formado por la Unión Europea, en los términos que ya hemos analizado en el apartado 2.A) de este trabajo; y por otro lado, se ha integrado en el nuevo y gran espacio común de la UE, tanto $i$ ) la política exterior y de seguridad común (PESC), incluida la política de defensa, como ii) la cooperación en justicia y asuntos de interior (JAI).

\section{- Integración de la PESC}

La política exterior y de seguridad común, y la política común de seguridad y defensa son integradas en lo que tradicionalmente se conocía como el ámbito comunitario, es decir, lo que hoy constituye la UE. Sin embargo, esta integración no va a producirse de manera plena, con completo sometimiento de estas políticas a las reglas comunes que van a regir la nueva UE. Por el contrario, la PESC y la PSD van a mantener un régimen especial, muy similar al que mantenían hasta el Tratado de Lisboa, tanto en lo que se refiere a los aspectos institucionales, como al proceso decisorio. Así, como establece el Art. 24.1 del TUE, "La política exterior y de seguridad común se regirá por reglas y procedimientos específicos". Por otra parte, se modifica la ordenación sistemática de esta materia en los Tratados, de tal manera que se distingue ahora entre, a) por un lado, las "disposiciones generales relativas a la acción exterior de la Unión y las disposiciones específicas relativas a la política exterior y de seguridad común", incluida la política común de seguridad y defensa, que son reguladas en el Tit. V del TUE (Arts. 21-46); y b) por otro lado, la «acción exterior de la Unión", en términos generales, que es regulada en la Quinta Parte del TFUE (Arts. 205-222), incluyendo en este apartado, tanto disposiciones generales relativas a la acción exterior de la Unión (Art. 205), como la política comercial común (Arts. 206-207), la cooperación con terceros países y la ayuda humanitaria (Arts. 208-214), las medidas restrictivas (Art. 215), los acuerdos internacionales (Arts. 216-219), las relaciones de la Unión con las organizaciones internacionales y con terceros países (Arts. 220-221), y la cláusula de solidaridad (Art. 222). 
En lo que se refiere al aspecto institucional, se introducen las figuras del Alto Representante para Asuntos Exteriores y Política de Seguridad, y del Presidente del Consejo Europeo, ambos con competencias en este terreno, además de la creación de un servicio europeo de acción exterior, como se verá más adelante. Y, en lo que se refiere al proceso decisorio, éste se ve flexibilizado, admitiéndose la posibilidad de decidir mediante mayoría cualificada en algunos casos. Se introducen, sin embargo, los denominados "frenos de emergencia", que permiten a los Estados miembros oponerse a la adopción de una decisión por mayoría cualificada en el Consejo y remitir un asunto al Consejo Europeo, cuando consideren que estén en juego sus intereses, "por motivos vitales y explícitos de política nacional" (Art. 31.2 del TUE). Por otra parte, se sustituye el viejo y complejo sistema de instrumentos a utilizar en este terreno —acciones comunes", "posiciones comunes", "estrategias comunes" (Art. 12 del viejo TUE)-, por sólo tres: "políticas comunes", "acciones" y "decisiones" (Arts. 21, 22, 26, 29 TUE).

Desde el punto de vista material, se desarrolla la política de defensa y se regulan las cooperaciones estructuradas permanentes. La "cooperación estructurada permanente" es una forma especial de cooperación reforzada, aplicable sólo en el ámbito de la defensa, que permite que los Estados miembros que tengan capacidades militares superiores puedan suscribir compromisos de mayor vinculación en este terreno, para realizar misiones más exigentes (Art. 42.6 del TUE).

En el ámbito específico de la ayuda humanitaria, se prevé la creación de un Cuerpo Voluntario Europeo de Ayuda Humanitaria, a fin de "establecer un marco para que los jóvenes europeos puedan aportar contribuciones comunes a las acciones de ayuda humanitaria de la Unión" (Art. 214.5 TFUE).

\section{- Integración de la JAI}

A diferencia de la PESC, la cooperación en justicia y asuntos de interior es integrada de lleno en el ámbito común de la nueva UE, con la intención de realizar de forma plena el espacio de libertad, seguridad y justicia. Todo lo cual supone el sometimiento del ámbito material de esta política al conjunto ordinario de las instituciones y de los instrumentos jurídicos de la Unión. En este sentido, la regulación del espacio de libertad, seguridad y justicia pasa ahora del TUE al TFUE y se convierte en el Título V de la Tercera Parte de éste Tratado (Arts. 67-89 TFUE).

Este ámbito, pues, es ahora objeto del procedimiento legislativo ordinario y de la adopción de decisiones por mayoría cualificada. Ello quiere decir también que desaparecen los instrumentos normativos utilizados hasta ahora en materia de cooperación policial y judicial — posiciones comunes", "decisiones marco", "decisiones", "Convenios" (Art. 34 del viejo TUE) — y son sustituidos por los instrumentos normativos ordinarios: reglamentos, directivas, decisiones (Art. 288 TFUE). 
Cabe incluir en este terreno también la creación de la Fiscalía Europea, que prevé el Art. 86 del TFUE, con el objetivo inicial limitado de perseguir las infracciones que perjudiquen a los intereses financieros de la Unión. Sin embargo, el mismo precepto establece igualmente la posibilidad de que el Consejo Europeo amplíe en el futuro las competencias de la Fiscalía Europea a la lucha contra la delincuencia grave de dimensión transfronteriza (Art. 86 TFUE).

Por lo demás, se mantienen los otros instrumentos tradicionales de cooperación en el ámbito judicial y policial, ya previstos con anterioridad, como Europol (Art. 88 TFUE) y Eurojust (Art. 85 TFUE). Eurojust, sin embargo, ve aumentadas sus competencias, al punto de atribuírsele el inicio de diligencias de investigación penal, así como la propuesta de incoación de procedimientos penales" (Art. 85.1 TFUE), lo que viene, en cierto modo, a incidir en la competencia de la Fiscalía Europea.

La integración plena de la cooperación judicial y policial en el ámbito de la UE y la realización del espacio de libertad, seguridad y justicia están sujetas también a garantías — -frenos de emergencia», que permiten a los Estados miembros oponerse a la adopción de una decisión por mayoría cualificada en el Consejo y remitir un asunto al Consejo Europeo, cuando consideren que esa decisión afecta a aspectos fundamentales de su sistema de justicia penal. Ello no puede evitar, sin embargo, que —en el supuesto de que no hubiese acuerdo en el Consejo Europeo- los Estados que quieran seguir adelante en la realización de aquella decisión, puedan hacerlo a través de una cooperación reforzada, lo que requiere el respaldo de, al menos, nueve Estados miembros (Arts. 82.3, 83.3 TFUE). Una medida similar de salvaguardia se encuentra en el Art. 86.1 del TFUE, en lo que se refiere a la regulación de Eurojust; y en el Art. 87.3 del TFUE, en lo que se refiere a la cooperación policial.

Por otra parte, se atribuye también aquí una nueva función de control a los Parlamentos nacionales, a través del ejercicio del mecanismo de control de la subsidiariedad. Mecanismo que, en este terreno, acentúa aún más la eficacia de este control parlamentario. Así, en el caso de proyectos de actos legislativos que afecten al espacio de libertad, seguridad y justicia, el umbral de los votos de los Parlamentos nacionales requeridos para oponerse a su tramitación se reduce de un tercio a sólo un cuarto de los votos (Art. 69 TFUE y Art. 7 del Protocolo $\mathrm{n}^{\circ} 2$ sobre la aplicación de los principios de subsidiariedad y proporcionalidad).

\section{- Parlamento Europeo}

El Parlamento Europeo aumenta su tamaño, hasta un total de 751 miembros ("no excederá de setecientos cincuenta, más el Presidente", dice el Art. 14 del TUE). ${ }^{25}$ Esta dimensión, a todas luces excesiva e innecesaria, convierte al

25 Dado que, según el Tratado de Niza, el número de miembros del Parlamento Europeo es 736, el Consejo Europeo de 11-12 de diciembre de 2008 acordó que, en el caso de que el Tratado de Lisboa entrase en vigor después de las elecciones europeas de junio de 2009, se aumen- 
Parlamento Europeo en un órgano mal dotado para el debate ágil y el desarrollo de una función de control más eficaz. A pesar de todo, el papel del Parlamento Europeo sale notablemente reforzado del Tratado de Lisboa, en varios aspectos.

En lo que se refiere a su función normativa, en primer lugar, su papel se ve fortalecido por el hecho mismo de la generalización del "procedimiento legislativo ordinario", que no sólo le pone en pié de igualdad con el Consejo, sino que le abre la posibilidad de pronunciarse sobre la gran mayoría de los asuntos en los que interviene la UE. En segundo lugar, por la modificación del procedimiento presupuestario, que extiende su potestad normativa a la totalidad del presupuesto, suprimiéndose la vieja distinción entre gastos obligatorios y gastos no obligatorios. Además, el Parlamento Europeo ha de aprobar también el marco financiero plurianual (las viejas perspectivas financieras), que pasa a ser fijado por el Consejo mediante reglamento (Arts. 312-316 del TFUE). Y, en tercer lugar, se refuerza su papel de control sobre los actos delegados (Art. 290 del TFUE) y los actos de ejecución —la "Comitología" (Art. 291 del TFUE), ocupando en estos procedimientos una posición igual a la del Consejo.

En segundo lugar, el Parlamento Europeo va a participar también de manera más activa en los procedimientos de revisión de los Tratados: dispone del poder de iniciativa, es consultado por el Consejo Europeo, participa en la Convención que se ha de convocar a estos efectos, y ha de expresar su aprobación, según cual sea el procedimiento que se siga (Art. 48 del TUE).

En tercer lugar, en lo que se refiere a los procesos de adhesión, se requiere ahora la previa aprobación del Parlamento Europeo (Art. 49 del TUE).

$\mathrm{Y}$, en cuarto lugar, en lo que se refiere al proceso de designación de la Comisión Europea, el Parlamento Europeo refuerza aún un poco más su papel, en línea con la "parlamentarización" de las relaciones Comisión-Parlamento que se inició con el Tratado de Maastricht y se continuó con los Tratados de Amsterdam y de Niza. Así, ahora se exige que, en el momento de designar al candidato a Presidente de la Comisión, el Consejo Europeo tenga en cuenta los resultados de las elecciones al Parlamento Europeo (Art. 17 del TFUE).

taría esa cifra hasta los 751 diputados previstos por el Tratado de Lisboa, hasta finales de la legislatura 2009-2014, permitiendo así que los doce Estados cuyo número de diputados se incrementa por el Tratado enviasen a los nuevos parlamentarios correspondientes. Pero, dado que, a la inversa, Alemania debería perder 3 diputados por la entrada en vigor del Tratado, se acordó también que los conservase hasta el final de la legislatura 2009-2014. De esta manera, a partir de la entrada en vigor del Tratado de Lisboa, y sólo por el tiempo que resta de la legislatura 20092014, el número de diputados del Parlamento Europeo pasará de 736 a 754 . (Consejo Europeo de Bruselas, 11 y 12 de diciembre de 2008, Conclusiones de la Presidencia, Anexo 1, Declaración del Consejo Europeo, Tratado de Lisboa - Medidas transitorias relativas a la composición del Parlamento Europeo (Bruselas, 11 y 12 de diciembre de 2008 (17271/08). 


\section{- Presidente del Consejo Europeo}

Se introduce la figura del Presidente del Consejo Europeo, como cargo permanente, elegido para un periodo de dos años y medio - renovable una sola vez-, por el propio Consejo Europeo, por mayoría cualificada. Esta nueva figura pretende dar una mayor visibilidad internacional y continuidad a la Presidencia de la UE, al mismo tiempo que dar un mayor impulso, mejor preparación, cohesión y continuidad a los trabajos del Consejo Europeo (Art. 15 del TUE).

El significado de esta figura no es algo pacífico. Inicialmente, su previsión por la Constitución europea parecía anunciar el establecimiento de la semilla de lo que, en el futuro, podría evolucionar hacia la consolidación de una presidencia electiva de la UE, en la medida en que el proceso de integración política de la UE se acentuase. Hoy, sin embargo, no parece ser esta la intención dominante entre los Gobiernos de los Estados miembros, la mayoría de los cuales parece preferir un Presidente del Consejo Europeo carente de liderazgo político y limitado a un papel secundario de dirección y gestión administrativa del Consejo Europeo. ${ }^{26}$

Desde luego, la designación del hasta entonces Primer Ministro belga, Herman van Rompuy - personalidad desconocida en el contexto europeo e internacional- como primer Presidente del Consejo Europeo, por el Consejo Europeo informal de Bruselas, de 19 de noviembre de 2009, es la manifestación más evidente de que los jefes de Estado o de Gobierno de la Unión no desean - al menos por lo de ahora - un nuevo dirigente político europeo que se coloque por encima de ellos y que ensombrezca su propio liderazgo. En mi opinión, todo ello es un grave error, dado que tratar de debilitar esta importante institución de la Unión, limitando su papel, sólo puede traer consigo un debilitamiento general de la UE y del papel que esta figura está formalmente llamada a jugar, tanto en el contexto interior como en el contexto internacional. Y este debilitamiento, no sólo perjudica al cargo en cuestión y a la UE —en términos institucionales- sino que nos debilita y perjudica a todos. ${ }^{27}$

\section{- Comisión Europea}

Se prevé la reducción del número de miembros de la Comisión Europea, cambiando el procedimiento que había introducido el Tratado de Niza a este

26 En este sentido, véase, por ejemplo, "BENELUX Memorandum: Implementatie van het Verdrag van Lissabon, 7 oktober 2009", en

http://europapoort.eerstekamer.nl/9345000/1f/j9vvgy6i0ydh7th/vi93kr48hdbj?top=vi9ng1y9xm8s

27 Vid. Decisión del Consejo Europeo de 1 de diciembre de 2009 por la que se elige al Presidente del Consejo Europeo (2009/879/UE) (DO L 315, 2.12.2009, p. 48); Decisión del Consejo de 1 de diciembre de 2009 por la que se fijan las condiciones de empleo del Presidente del Consejo Europeo (2009/909/UE) (DO L 322, 9.12.2009, p. 35); y Decisión del Consejo Europeo, de 1 de diciembre de 2009, relativa a la adopción de su Reglamento interno (2009/882/UE) (DO L 315, 2.12.2009). 
respecto y manteniendo, en cambio, lo establecido por el Tratado constitucional. Así, se establece que, si bien la Comisión estará compuesta por un nacional de cada Estado miembro hasta el 31 de octubre de 2014, a partir del 1 de noviembre de ese año, la Comisión tendrá un número de miembros igual a los dos tercios del número de Estados de la UE, incluyendo a su Presidente y al Alto Representante de la Unión para Asuntos Exteriores y Política de Seguridad - a menos que el Consejo Europeo decida por unanimidad modificar dicho número- De esta manera, los miembros de la Comisión serán seleccionados de entre los nacionales de los Estados miembros mediante un sistema de rotación entre los Estados, que ha de ser adoptado por unanimidad por el Consejo Europeo (Art. 17 TUE).

Esta previsión, sin embargo, ha sido vaciada de contenido por el acuerdo conseguido en el Consejo Europeo de 11-12 de diciembre de 2008 y ratificado por el Consejo Europeo de 18-19 de junio de 2009, para solucionar el problema de Irlanda. Según este acuerdo, el Consejo Europeo se comprometió, entre otras cosas, a adoptar una decisión a fin de que la Comisión siga incluyendo en el futuro a un nacional de cada Estado miembro, si Irlanda celebraba un nuevo referéndum sobre el Tratado de Lisboa con resultado positivo y el Tratado entraba finalmente en vigor. La decisión del Consejo Europeo supone un claro paso atrás en la línea de reforma de la Comisión Europea tendente a reducir su número de miembros y a buscar con ello una mayor funcionalidad y eficiencia; sin embargo, tiene sostén jurídico en el Tratado de la Unión Europea, el cual — como se acaba de ver- permite, en su Art. 17.5, que el Consejo Europeo cambie, por unanimidad, dicho número.

\section{- Alto Representante de la Unión para Asuntos Exteriores y Política de Seguridad}

Se introduce la figura del Alto Representante de la Unión para Asuntos Exteriores y Política de Seguridad, basada en el cargo de "Ministro de Asuntos Exteriores de la Unión", que preveía la Constitución europea (Art. I-28), cuyas funciones son sustancialmente mantenidas. El Alto Representante es nombrado por el Consejo Europeo, por mayoría cualificada, con la aprobación del Presidente de la Comisión (Art. 18 del TUE).

Lo peculiar de esta figura es que va a ser, al mismo tiempo, un miembro del Consejo y de la Comisión. De esta manera, el Alto Representante estará al frente de la política exterior y de seguridad común de la Unión y, en tal condición, presidirá el Consejo de Asuntos Exteriores. Pero, al mismo tiempo, será uno de los Vicepresidentes de la Comisión, encargado de las responsabilidades que incumben a ésta en el ámbito de las relaciones exteriores (Art. 18 del TUE). Se pretende así dar una mayor visibilidad y coherencia a la acción exterior de la UE. Sin embargo, este doble papel puede resultar conflictivo y se requerirá todavía un tiempo para que se pueda comprobar la funcionalidad o disfuncionalidad de esta estructura, más allá de lo oportuno y lo necesario de la institución en sí misma. 
La designación de Catherine Margaret Ashton, Baronesa de Upholland, persona carente de experiencia en el terreno de las relaciones internacionales (fue sólo durante un año, desde octubre de 2008, miembro de la Comisión Europea, encargada de Comercio), como la primera Alta Representante, es una clara manifestación de la voluntad de los Estados de no dar a este nuevo cargo la relevancia que debería tener y que preveía la Constitución europea, para poder satisfacer la profunda y largamente sentida necesidad de que la UE ocupe en el contexto internacional el peso que debe corresponder a su propio peso económico. Es sorprendente y, al mismo tiempo, muy frustrante que los dirigentes políticos europeos hayan dado en este terreno un paso tan grande hacia atrás, al nombrar a una persona con méritos y experiencia profesionales mucho menores que los que poseía ya quien era el anterior Alto Representante —Javier Solana. Cabe decir aquí —al igual que en el caso del Presidente del Consejo Europeo- que carece totalmente de sentido crear una institución con tantas posibilidades - y expectativas - para luego tratar de cercenar su funcionalidad y eficacia, con una corta perspectiva nacionalista. ${ }^{28}$

La actuación del Alto Representante se verá apoyada por la creación de un servicio europeo de acción exterior, el cual estará compuesto por funcionarios de la Secretaría General del Consejo y de la Comisión, y por personal —en comisión de servicios- de los servicios diplomáticos nacionales (Art. 27 del TUE).

\section{- Tribunal de Justicia}

El Tribunal de Justicia ve ampliada su jurisdicción, que va a cubrir ahora el conjunto de las actividades de la UE, con excepción de la política exterior y de seguridad común; si bien quedan en este terreno también bajo su jurisdicción las decisiones adoptadas por el Consejo por las que se establezcan medidas restrictivas frente a personas físicas o jurídicas (Art. 24 del TUE; y Arts. 215 y 275 del TFUE).

Desde el punto de vista estructural, el Tratado de Lisboa no introduce aquí cambios sustanciales, dado que tanto él, como la Constitución europea en la que se basa, toman las modificaciones introducidas por el Tratado de Niza. En este sentido, el Tribunal de Justicia de la Unión Europea, como institución de la Unión (Art. 13.1 TUE), pasa a comprender tres tipos de órganos: el Tribunal de Justicia, el Tribunal General y los tribunales especializados (Art. 19 TUE). El Tribunal de Justicia podrá actuar en Pleno, en Gran Sala o en Sa-

28 Vid. Decisión del Consejo Europeo, adoptada con la aprobación del Presidente de la Comisión, de 4 de diciembre de 2009 por la que se nombra al Alto Representante de la Unión para Asuntos Exteriores y Política de Seguridad (2009/950/UE) (DO L 328, 15.12.2009, p. 69); Decisión del Consejo de 1 de diciembre de 2009 por la que se fijan las condiciones de empleo del Alto Representante de la Unión para Asuntos Exteriores y Política de Seguridad (2009/910/UE) (DO L 322, 9.12.2009, p. 36); y Decisión del Consejo de 1 de diciembre de 2009 por la que se aprueba su Reglamento interno (2009/937/UE) (DO L 325, 11.12.2009, p. 36). 
las, según prevé el Tratado y el Estatuto del Tribunal de Justicia de la Unión Europea (Art. 251 TFUE, y Protocolo (no 3 ) sobre el Estatuto del Tribunal de Justicia de la Unión Europea). ${ }^{29} \mathrm{El}$ Tribunal General (Art. 256 TFUE) reemplaza al viejo Tribunal de Primera Instancia y, en lo que se refiere a los tribunales especializados, hasta el presente, sólo ha sido creado uno: el Tribunal de la Función Pública de la Unión Europea. ${ }^{30}$

Hay, en cambio, algunas novedades en otros aspectos, como, por ejemplo, la constitución de un comité, compuesto por siete personalidades del mundo de la judicatura y del Derecho, de reconocida competencia, para que se pronuncie sobre la idoneidad de los candidatos para ser juez o abogado general del Tribunal de Justicia y del Tribunal General, antes de que los Gobiernos de los Estados procedan a su nombramiento (Art. 255 TFUE). Por otra parte, a exigencia de Polonia, se formuló la Declaración $n^{\circ} 38$, que permite al Consejo, por unanimidad, aumentar el número de abogados generales del Tribunal de Justicia. ${ }^{31}$ En este caso, Polonia - como ya ocurre con Alemania, Francia, Italia, España y el Reino Unido- tendría un abogado general permanente y no participaría ya en el sistema rotatorio de designación de abogados generales.

\section{- Parlamentos nacionales}

Los Parlamentos nacionales entran de lleno en el proceso europeo y se les va a atribuir una posición aún más reforzada que la que ya les atribuía la Constitución europea. Así, se introducen dos nuevos preceptos (Art. 12 TUE y Art. 69 TFUE) que regulan por primera vez, de manera específica, el papel de los Parlamentos nacionales en la UE. A los Parlamentos nacionales se les da ahora la posibilidad de participar, con diferente grado de implicación, a) en el procedimiento legislativo — control de la aplicación del principio de subsidiariedad-; $b$ ) en la evaluación de las políticas de la UE en el marco del espacio de libertad, seguridad y justicia; $c$ ) en los procedimientos de revisión de los Tratados; y $d$ ) en los procedimientos de adhesión a la UE (Art. 12 TUE).

De los mecanismos de participación previstos, quizá sean dos los que tengan una mayor incidencia en el funcionamiento ordinario de la UE: los incluidos en el "Protocolo ( ${ }^{\circ}$ 1) sobre el cometido de los Parlamentos nacionales en la Unión Europea" ${ }^{32}$ y en el "Protocolo ( ${ }^{\circ}$ 2) sobre la aplicación de los principios de subsidiariedad y proporcionalidad,. ${ }^{33}$ En el primero de ellos, que obliga a que los Parlamentos nacionales sean informados de todos los proyectos de actos legislativos que se vayan a tramitar, el Tratado de Lisboa aumenta a 8 semanas (eran 6 en la Constitución europea) el plazo que se con-

29 DO C $115,9.5 .2008$, p. 210.

30 Creado por la Decisión del Consejo de 2 de noviembre de 2004 (DO, L 333, 9.11.2004).

31 DO C $115,9.5 .2008$, p. 350.

32 DO C $115,9.5 .2008$, p. 203.

33 DO C 115, 9.5.2008, p. 206. 
cede a los Parlamentos nacionales para examinar los proyectos y para formular su dictamen motivado al respecto. Además, cuando el Consejo Europeo prevea hacer uso de las denominadas "cláusulas pasarela" previstas en el Art. 48.7 del TUE, deberá informar a los Parlamentos nacionales de la iniciativa, al menos, seis meses antes de que adopte la decisión, bastando la oposición de un solo Parlamento nacional, manifestada en el plazo de seis meses a partir de la notificación de la iniciativa, para que ésta no pueda ser adoptada. Una medida similar se incluye en el Art. 81.3 del TFUE, en lo que se refiere a la cooperación judicial en materia civil: así, cuando el Consejo vaya a adoptar una decisión que afecte a aspectos del Derecho de familia con repercusión transfronteriza mediante el procedimiento legislativo ordinario, habrá de comunicarlo previamente a los Parlamentos nacionales, bastando que uno de ellos manifieste su oposición, en los seis meses posteriores a la comunicación, para que la decisión no pueda ser adoptada.

$\mathrm{Y}$, en el segundo - el "Protocolo $\mathrm{n}^{\circ} 2$-, se prevé la posibilidad de que los Parlamentos nacionales se pronuncien sobre si los proyectos de actos legislativos a tramitar vulneran o no el principio de subsidiariedad. Se distinguen aquí dos mecanismos, denominados en la jerga comunitaria y con símil futbolístico: "tarjeta amarilla" y "tarjeta naranja". El primer mecanismo — "tarjeta amarilla - , previsto en el Art. 7.2 del Protocolo, se establece para cualquier tipo de procedimiento normativo, excepto el ordinario, y supone que, si los Parlamentos nacionales que representen un tercio del total de votos atribuidos (cada Parlamento nacional dispone de 2 votos; uno por Cámara, si hay más de una) consideran que un acto legislativo no respeta el principio de subsidiariedad, el proyecto deberá volver a ser estudiado por la institución que presentó el proyecto. Ésta, mediante acto motivado, podrá entonces mantener, modificar, o retirar su propuesta.

El segundo mecanismo — «tarjeta naranja» está previsto en el Art. 7.3 del Protocolo, y se establece exclusivamente para el procedimiento legislativo ordinario. De acuerdo con este mecanismo, cuando los dictámenes motivados de los Parlamentos nacionales que reúnan la mayoría simple de los votos atribuidos, entiendan que una propuesta no respeta el principio de subsidiariedad, ésta deberá volver a ser estudiada. La Comisión podrá, en este momento, mantener, modificar, o retirar la propuesta. Si decide mantenerla, en el procedimiento legislativo, antes de que concluya la primera lectura, el Consejo y el Parlamento Europeo analizarán la compatibilidad de la propuesta legislativa con el principio de subsidiariedad, atendiendo a las motivaciones presentadas por la mayoría de los Parlamentos nacionales y al dictamen motivado de la Comisión. Entonces, si, por mayoría del $55 \%$ de los miembros del Consejo, o por mayoría de los votos emitidos del Parlamento Europeo, el legislador considera que la propuesta no es compatible con el principio de subsidiariedad, ésta es desestimada.

La participación de los Parlamentos nacionales en el proceso europeo, tan demandada en determinados sectores, con la pretensión de atenuar el denominado "déficit democrático" de la UE, resulta a todas luces disfuncional y des- 
proporcionada. Es disfuncional porque la legitimidad democrática y la función representativa que puedan aportar a este proceso es ya $-\mathrm{y}$ ha de ser- $\mathrm{cu}-$ bierta por el Parlamento Europeo y, por lo tanto, tratar de introducir este nuevo elemento representativo en el sistema, lejos de reforzar el carácter democrático del mismo, lo debilita, porque no refuerza el elemento representativo propio de la Unión - el Parlamento Europeo-y, por el contrario, introduce un conflicto de representatividad y de legitimidades en el sistema; y, además, lejos de favorecer el proceso decisorio, lo hace aún —como se ha visto- más largo y complejo. Y es desproporcionada porque no sólo se puede llegar a bloquear la adopción de decisiones por parte de la UE, cuando un determinado número de Parlamentos nacionales se oponga a las mismas - con ignorancia de lo que pueda decidir el Parlamento Europeo al respecto-, con base en un concepto jurídico indeterminado, claramente político y muy difícil de delimitar, como es el principio de subsidiariedad, sino que un solo Parlamento nacional, por muy pequeño que sea el Estado al que represente, puede llegar a bloquear por sí mismo una decisión de la UE cuando — como ya se ha visto- ésta suponga la utilización por el Consejo Europeo de las denominadas "cláusulas pasarela" (Art. 48.7 del TUE), o cuando se trate de medidas referidas al Derecho de familia (Art. 81.3 del TFUE). En este sentido, pues, lo que se prevé en los Tratados como mecanismos de flexibilidad o de acentuación del proceso de integración europea, pueden ser bloqueados por un solo Parlamento nacional, y esto es desproporcionado y absolutamente indeseable en una UE de 27 Estados, que pueden ser varios más en un futuro no demasiado lejano.

La participación de los Parlamentos nacionales en el proceso europeo, pues, es innecesaria y, lejos de contribuir a la dinámica de integración, puede suponer un serio freno a la misma, por cuanto implica un reforzamiento del peso de la dimensión intergubernamental en el seno de la UE.

\section{- Participación de las Regiones}

El Tratado de Lisboa atribuye un papel mayor a las Regiones en el proceso europeo y eleva el nivel de su reconocimiento político, al considerar la "autonomía local y regional" como una parte de la identidad nacional de los Estados miembros, inherente a sus estructuras fundamentales políticas y constitucionales (Art. 4.2 TUE). Su mayor participación activa se deriva no sólo de la extensión del papel del Comité de las Regiones, sino también de su participación en el mecanismo de control de la aplicación del principio de subsidiariedad.

Así, el Art. 5 del TUE establece ahora que, en virtud del principio de subsidiariedad, la Unión intervendrá sólo en caso de que los objetivos de la acción pretendida no puedan ser alcanzados de manera suficiente por los Estados miembros "ni a nivel central ni a nivel regional y local". Y, en desarrollo de esta previsión, el mencionado Protocolo $\mathrm{n}^{\circ} 2$ sobre la aplicación de los principios de subsidiariedad y proporcionalidad, establece que, en las con- 
sultas que han de preceder a las propuestas de actos legislativos, la Comisión deberá tener en cuenta, cuando proceda, "la dimensión regional y local" de las acciones previstas (Art. 2), a lo que se añade, además, que los proyectos de actos legislativos deben procurar que cualquier carga que impliquen sea lo más reducida posible y proporcional al objetivo que se desea alcanzar, ya recaiga ésta sobre los Gobiernos nacionales, o sobre "las autoridades regionales o locales" (Art. 5).

Por otra parte, en la formulación de su respectivo dictamen motivado en el que se expongan las razones por las que un Parlamento nacional considera que un proyecto no se ajusta al principio de subsidiariedad, este Parlamento habrá de "consultar, cuando proceda, a los Parlamentos regionales que posean competencias legislativas" (Art. 6 del Protocolo $\mathrm{n}^{\circ} 2$ ).

En lo que se refiere al refuerzo del papel del Comité de las Regiones, el Tratado de Lisboa, siguiendo las previsiones de la Constitución europea, aumenta a cinco años el mandato de sus miembros (Art. 305 TFUE; el Art. 263 TCE preveía cuatro años) y establece también como preceptiva la consulta del Parlamento Europeo - además de la del Consejo y de la Comisión- en los casos previstos en los Tratados (Art. 307 TFUE; el Art. 265 TCE preveía la consulta del Parlamento Europeo sólo como facultativa). Además, el Comité de las Regiones podrá también interponer recursos ante el Tribunal de Justicia contra actos legislativos para cuya adopción el TFUE requiera su dictamen (Art. 8 del Protocolo $n^{\circ} 2$ ) y, en todo caso, en defensa de sus propias competencias (Art. 263 TFUE). En fin, en esta línea, la Comisión ha de presentar al Comité de las Regiones un informe anual sobre la aplicación del articulo 5 del TUE, en lo que se refiere a los principios de subsidiariedad y de proporcionalidad (Art. 9 del Protocolo $n^{\circ} 2$ ).

b) Reformas de carácter material

\section{- Valores fundamentales y objetivos de la Unión}

El Tratado de Lisboa introduce en el TUE dos de los artículos iniciales del Tratado constitucional (Arts. I-2 y I-3), uno precisando los valores fundamentales de la Unión, y otro los objetivos de la misma (Arts. 2 y 3 del TUE). El viejo TUE y el TCE carecían de una fórmula similar que definiese los valores superiores que inspiran la constitución y el funcionamiento de la UE, y éste era un vacío que la conformación constitucional de la Unión debía cubrir. El fracaso de la Constitución europea no ha impedido, sin embargo, que estos preceptos — sobre todo el referido a los valores - pasasen en su integridad al nuevo TUE.

Así, en su formulación actual, el Art. 2 del TUE establece que "La Unión se fundamenta en los valores de respeto de la dignidad humana, libertad, democracia, igualdad, Estado de Derecho y respeto de los derechos humanos, incluidos los derechos de las personas pertenecientes a minorías", añadiendo que 
"Estos valores son comunes a los Estados miembros en una sociedad caracterizada por el pluralismo, la no discriminación, la tolerancia, la justicia, la solidaridad y la igualdad entre mujeres y bombres".

Algunos de estos valores, reformulados en términos de derechos fundamentales, forman hoy parte también de la Carta de los de Derechos Fundamentales de la UE. En este sentido, pues, hay un hilo de continuidad entre la Carta y los valores de la Unión y de aquí también el hecho de que podamos sostener - como se dijo en páginas anteriores - que la Carta, junto con los valores de la Unión, en los que se fundamenta, forman el aparato dogmático de la estructura constitucional de la UE.

En lo que se refiere a los objetivos, el actual Art. 3 de TUE viene a ser una refundición del contenido del Art. 2 del viejo TUE y del Art. 2 del TCE. En realidad, más que fijar objetivos, el actual Art. 3 de TUE lo que hace es definir el contenido sustantivo de la UE. Así, además de establecer inicialmente que la finalidad de la UE es "promover la paz, sus valores y el bienestar de sus pueblos" (párrafo 1), no sólo en el interior, sino también en sus relaciones con el resto del mundo (párrafo 5), el resto de los párrafos del Art. 3 del TUE lo que hace es describir la UE, como "un espacio de libertad, seguridad y justicia sin fronteras interiores, en el que esté garantizada la libre circulación de personas", "un mercado interior", y "una unión económica y monetaria cuya moneda es el euro".

\section{- Personalidad jurídica de la UE}

El Tratado de Lisboa atribuye personalidad jurídica a la UE y esta atribución es recogida en el Art. 47 del TUE. Con anterioridad, la personalidad jurídica era un predicado sólo de la Comunidad Europea (Art. 281 TCE) y de la Comunidad Europea de la Energía Atómica (Art. 184 TCEEA), con lo cual, la UE —en cuanto que tal- carecía de reconocimiento jurídico internacional y no podía entablar relaciones jurídicas contractuales con otras instancias nacionales o internacionales: sólo lo podían hacer las Comunidades Europeas, y sólo dentro de su respectivo ámbito material.

El cambio estructural-constitucional que lleva a la creación de la nueva UE hace que la Comunidad Europea se diluya en su seno y que, por tanto, la Unión asuma todo el componente jurídico y material del que aquélla estaba compuesta, incluida su personalidad jurídica. Lo dice así, con toda claridad, el apartado tercero del Art. 1 del TUE: "La Unión sustituirá y sucederá a la Comunidad Europea". De aquí, pues, que la UE goce hoy también de personalidad jurídica.

\section{- Delimitación de competencias}

La delimitación de competencias entre la Unión y los Estados miembros es uno de los temas de la reforma que mayor interés político ha suscitado a lo largo de los años que precedieron a la formulación de la Constitución euro- 
pea. Y no precisamente porque se pretendiese con ello salvaguardar o, incluso, aumentar la competencia de la Unión frente a los Estados miembros, sino, más bien al contrario, para frenar la expansión progresiva de su ámbito competencial que el sistema funcional de distribución de competencias, hasta entonces existente, había permitido. En este sentido, es evidente que el ámbito competencial de lo que hoy es la Unión Europea ha experimentado una extraordinaria expansión, con respecto a lo que inicialmente se había atribuido a las Comunidades Europeas en el momento de su fundación, en los años cincuenta del siglo pasado. Y esta expansión se produjo, no sólo por la reforma de los Tratados, sino también a través de la mutación constitucional producida por la jurisprudencia expansiva del Tribunal de Justicia, basada tanto en la teoría de los poderes implícitos, como en la previsión de las cláusulas abiertas de los Tratados y, fundamentalmente, en el Art. 308 del TCE.

La exigencia, pues, de los sectores más reacios al proceso expansivo de la integración europea es lo que llevó a incluir la cuestión del reparto de competencias en el punto primero de la agenda de la Declaración relativa al futuro de la Unión, del Consejo Europeo de Niza, de diciembre del 2000 ( "la delimitación más precisa de las competencias entre la UE y los Estados miembros", se decía allí) y de la agenda de la Declaración sobre el Futuro de la Unión Europea, del Consejo Europeo de Laeken, de diciembre de 2001 ( "un mejor reparto y definición de las competencias de la Unión", se dijo entonces, anunciando ya una opción más restrictiva). La reforma del sistema de competencias de la UE que el Tratado de Lisboa introduce en los Tratados actuales es, por tanto, el resultado de este debate y traslada a los mismos —al pié de la letra- las previsiones de la racionalización de este sistema que, con ese objetivo limitador, hizo la Constitución europea.

Así, los Tratados no sólo realizan ahora una clara y rígida delimitación de competencias entre la Unión y los Estados miembros (competencias exclusivas de la UE, competencias compartidas entre la UE y los Estados miembros, competencias de coordinación, y competencias de apoyo o complemento, además de las competencias en política exterior y de seguridad común: Arts. 2-6 TFUE), sino que afirman de manera reiterada el principio de atribución, según el cual "la Unión actúa dentro de los limites de las competencias que le atribuyen los Estados miembros en los Tratados para lograr los objetivos que éstos determinan" (Art. 5.2 TUE), y, consiguientemente, la competencia residual de los Estados; por lo que "Toda competencia no atribuida a la Unión en los Tratados corresponde a los Estados miembros" (Arts. 4.1 y 5.2 TUE)

Por otra parte, además, se afirma de manera explícita la posibilidad de modificar los Tratados, no sólo para aumentar, sino también - y esto es lo más llamativo_ - para reducir las competencias atribuidas a la Unión (Art. 48.2 del TUE).

A mayor abundamiento, la Declaración ( $n^{\circ}$ 18) relativa a la delimitación de las competencias, aneja al Acta Final de la CIG 2007, no sólo reafirma — de manera innecesaria- el principio de atribución y la competencia residual de los Estados miembros, así como la posibilidad de modificar los Tratados, 
para aumenta o reducir las competencias de la Unión - ya previstos formalmente en el articulado de los Tratados-, sino que, en la medida en que - en el ámbito de las competencias compartidas- los Estados miembros no pueden ejercer su competencia cuando la Unión haya ejercido la suya, se propone que el Consejo pueda pedir a la Comisión que presente propuestas de derogación de actos legislativos de la Unión, a fin de que los Estados puedan recuperar su capacidad de acción — su competencia - en esos terrenos específicos, utilizando la excusa del respeto de los principios de subsidiariedad y de proporcionalidad. ${ }^{34}$

Es evidente, pues, que, a diferencia de lo ocurrido desde la fundación de las Comunidades Europeas hasta nuestros días, la distribución de competencias entre la UE y los Estados miembros se fundamenta hoy, más en la desconfianza y en el recelo frente a la acentuación del proceso de integración europea, que en la mutua confianza y en el apoyo decidido de este proceso.

\section{- Democracia participativa y representativa}

Los Tratados regulan ahora de manera explícita el principio representativo y tratan de reforzar con ello el carácter democrático de la Unión. Aspecto éste que la Constitución europea trató de sistematizar y de enfatizar en su momento y que pasa ahora íntegramente a los Tratados. Así, se definen con precisión los principios y los cauces democráticos del sistema político de la UE y se refuerza la democracia participativa. En este sentido, el Tratado distingue entre $a$ ) democracia representativa y $b$ ) lo que cabría denominar como democracia participativa.

a) En lo que se refiere a la democracia representativa, el Art. 10 del TUE establece que los ciudadanos estarán directamente representados en la Unión a través del Parlamento Europeo, mientras que los Estados miembros estarán representados en el Consejo Europeo y en el Consejo, "que serán democráticamente responsables, bien ante sus Parlamentos nacionales, bien ante sus ciudadanos". Y, al mismo tiempo, establece también que "los partidos politicos a escala europea contribuirán a formar la conciencia política europea y a expresar la voluntad de los ciudadanos de la Unión", recogiendo en esto la vieja previsión del Art. 191 del TCE. ${ }^{35}$

Por otra parte, debe mencionarse aquí también el importante papel que el Art. 12 del TUE atribuye a los Parlamentos nacionales en el funcionamiento de la UE, lo cual no sólo supone - en la concepción de algunos- una contribución a la mayor legitimidad de la UE y a cubrir su supuesto déficit democrático, sino que el propio TUE incluye su regulación en el Tit. II, dedicado preci-

34 DO C 115, 9.5.2008, p. 344.

35 Sobre el papel de los partidos políticos europeos, véase: Reglamento (CE) nº 2004/2003 del Parlamento Europeo y del Consejo, de 4 de noviembre de 2003, relativo al estatuto y la financiación de los partidos políticos a escala europea (DO L 297, 15.11.2003), modificado por el Reglamento (CE) n ${ }^{\circ}$ 1524/2007 del Parlamento Europeo y del Consejo, de 18 de diciembre de 2007 (DO L 343 de 27.12.2007, pp. 5-8). 
samente a los principios democráticos de la Unión. De ello nos hemos ocupado ya en el apartado de este trabajo dedicado a las reformas institucionales.

b) En lo que se refiere a la democracia participativa, el Art. 11 del TUE obliga a las instituciones a dar a los ciudadanos y a las asociaciones representativas la posibilidad de expresar e intercambiar públicamente sus opiniones en todos los ámbitos de actuación de la Unión y a mantener un "diálogo abierto, transparente y regular" con estas últimas.

En este ámbito, se introduce la iniciativa legislativa popular, que requiere el respaldo de, al menos, un millón de ciudadanos de la Unión, "que sean nacionales de un número significativo de Estados miembros". Iniciativa que ha de ser dirigida a la Comisión Europea, para que sea ella la que, en el marco de sus atribuciones, presente formalmente la propuesta adecuada (Art. 11.4 del TUE). ${ }^{36}$

En esta línea, debe ser destacada aquí también la regulación que se hace en el Art. 15 del TFUE del principio de apertura, tanto en el sentido de exigir que las sesiones del Parlamento Europeo, así como las del Consejo en las que éste delibere y vote sobre un proyecto de acto legislativo (Art. 16.8 TUE), sean públicas, como en el sentido de permitir a los ciudadanos el acceso a los documentos de las instituciones y organismos de la Unión, "cualquiera que sea su soporte". Algo que, sin embargo, preveían ya en buena medida los Arts. 207.3 y 255 del TCE. ${ }^{37}$

\section{- Procedimientos legislativos}

Como se analiza en el apartado dedicado a los instrumentos normativos de la Unión, uno de los aspectos importantes de la reforma de la UE que exigían tanto la Declaración de Niza, del año 2000, como la Declaración de Laeken, del año 2001, era la simplificación del ordenamiento jurídico de la Unión, lo que, con toda evidencia, está íntimamente relacionado con la concepción del procedimiento normativo que se vaya a seguir.

En este sentido, la reforma de la Constitución europea distinguía entre "actos legislativos", adoptados mediante un procedimiento legislativo —ordinario o especial - y con una posición jerárquica superior, y "actos no legislativos", con una posición jerárquica inferior, que eran todos los demás, cualquiera que fuere el procedimiento seguido para su elaboración. El Tratado de Lisboa, a pesar de que no recoge la diferente denominación de los instru-

36 Sobre esta cuestión, véase la Resolución del Parlamento Europeo, de 7 de mayo de 2009, por la que se solicita a la Comisión que presente una propuesta de Reglamento del Parlamento Europeo y del Consejo relativo a la aplicación de la iniciativa ciudadana (2008/2169(INI)); y Commission of the European Communities, Green Paper on a European Citizens' Initiative (Brussels, 11.11.2009, $\operatorname{COM}(2009) 622$ final).

37 Sobre el derecho de acceso a los documentos, véase el Reglamento (CE) nº 1049/2001 del Parlamento Europeo y del Consejo, de 30 de mayo de 2001, relativo al acceso del público a los documentos del Parlamento Europeo, del Consejo y de la Comisión (DO L 145, 31.5.2001), y el Art. 42 de la CDFUE. 
mentos normativos que introducía la Constitución europea, sí toma, en cambio, todos los demás aspectos de la reforma del ordenamiento jurídico de la UE que aquélla preveía.

Así, el TFUE recoge ahora la sustancia de aquella reforma y estructura el proceso normativo de la Unión en dos grandes bloques: $a$ ) el "procedimiento legislativo" y b) los demás procedimientos, que, claro es, son "no legislativos". Y el procedimiento legislativo se subdivide, a su vez, en dos: $i$ ) el "procedimiento legislativo ordinario", y ii) los "procedimientos legislativos especiales".

El "procedimiento legislativo ordinario", se corresponde con el procedimiento hasta ahora denominado procedimiento de "codecisión", que era regulado por el Art. 251 del TCE. En los términos actuales del Art. 289.1 del TFUE, el procedimiento legislativo ordinario consiste en la adopción conjunta por el Parlamento Europeo y el Consejo, a propuesta de la Comisión, de un reglamento, una directiva o una decisión. Este procedimiento figura ahora detallado en el Art. 294 del TFUE.

Este procedimiento, pues, implica al Parlamento Europeo y al Consejo, que participan en el mismo en pié de igualdad —el "legislador de la Unión»—, ${ }^{38}$ previa iniciativa —que es exclusiva sólo en este procedimientode la Comisión Europea; y el producto del mismo, como se indica, sólo pueden ser reglamentos, directivas o decisiones, que tienen carácter "legislativo" y, por lo tanto, un rango normativo superior en la jerarquía normativa del Derecho de la Unión. La reforma del Tratado de Lisboa, pues, convierte a este procedimiento - como su denominación indica con toda claridad- en el procedimiento general, aplicable a la práctica totalidad de las materias reguladas en los Tratados. De hecho, el procedimiento legislativo ordinario se extiende a un total de 76 bases jurídicas.

Los "procedimientos legislativos especiales" —según el Art. 289.2 del TFUE - son aquéllos en los que, bien el Parlamento Europeo adopta un acto con la participación del Consejo, bien es el Consejo el que adopta un acto con la participación del Parlamento Europeo. Estos procedimientos sirven también para la adopción de reglamentos, directivas o decisiones, que tienen igualmente carácter "legislativo" y, por lo tanto, un rango normativo superior en la jerarquía normativa del Derecho de la UE, y, sin embargo, no se producen de acuerdo con un procedimiento igual, sino en la forma particular que prevé el TFUE en cada caso. En este sentido, las fórmulas empleadas por el TFUE suelen prever, por un lado, la decisión del Consejo "por unanimidad, previa aprobación del Parlamento Europeo" (i.e. Arts. 19, 25, 86, 312 TFUE), o "por unanimidad, previa consulta al Parlamento Europeo" (i.e. Arts. 21, 22, 64, 77, 81, 87, 89, 118, 194, 262, 311, 333 TFUE); y, por otro lado, la decisión del Parlamento Europeo "por propia iniciativa, previa aprobación del Consejo y de la Comisión"

38 La denominación "legislador de la Unión", para referirse al Parlamento Europeo y al Consejo, actuando conjuntamente en función legislativa, es utilizada formalmente por los Arts. 4 y 7.3 del Protocolo $\left(n^{\circ} 2\right)$ sobre la aplicación de los principios de subsidiariedad y proporcionalidad (DO C $115,9.5 .2008$, p. 206). 
(i.e. Art. 226 TFUE), o "por propia iniciativa, previo dictamen de la Comisión y con la aprobación del Consejo por unanimidad" (i.e. Art. 223 TFUE).

Lo característico de estos procedimientos legislativos especiales es, por tanto, la participación del Parlamento Europeo y del Consejo en posición de desigualdad - no como colegisladores-, su activación por iniciativa propia o de otras instituciones (Comisión, BEI), la posible consulta a otras instituciones (CES, CdR, BCE), y la exigencia de otro tipo de mayorías en el Consejo y en el Parlamento Europeo. En todo caso, la utilización de estos procedimientos es mucho menor que la del procedimiento legislativo ordinario, y recae sólo sobre 36 bases jurídicas.

En definitiva, pues, poniendo en relación a los procedimientos normativos introducidos por el Tratado de Lisboa, con el principio de la jerarquía normativa, nos encontramos con que el TFUE distingue ahora entre "actos legislativos", que son aquellos adoptados mediante un procedimiento legislativo —ordinario o especial - y con una posición jerárquica superior - ya sean reglamentos, directivas, o decisiones- (Art. 289 TFUE), y "actos no legislativos", con una posición jerárquica inferior, que son todos los demás, cualquiera que fuere el procedimiento seguido para su elaboración - delegación legislativa, competencia ejecutiva conferida, competencia normativa autónoma-, la autoridad emanante de la norma - Consejo, Comisión, Parlamento Europeo, Banco Central Europeo, Agencia reguladora-, o el tipo de acto en cuestión — reglamentos, directivas, decisiones, recomendaciones- (Arts. 290-292 y otros del TFUE).

\section{- Mayoría cualificada}

El Tratado de Lisboa introduce el sistema de doble mayoría para definir la mayoría cualificada en el Consejo, y, además, extiende este procedimiento como la norma general para la adopción de decisiones en el Consejo. Así, la mayoría cualificada, cuando el Consejo actúe a propuesta de la Comisión o del Alto Representante de la Unión para Asuntos Exteriores y Política de Seguridad, se define como el 55\% de los Estados - que incluya, al menos, 15 de ellos- que representen, como mínimo, al 65\% de la población de la UE. Cuando sea otra la instancia proponente, la mayoría cualificada exigirá un mínimo del $72 \%$ de los Estados que representen, al menos, el $65 \%$ de la población. Se exige, además, que la minoría de bloqueo esté compuesta, al menos, por 4 Estados miembros (Arts. 16 del TUE y 238 del TFUE).

Este nuevo procedimiento de votación sólo entrará en vigor a partir del 1 de noviembre de 2014. Sin embargo, se establecen disposiciones transitorias en virtud de las cuales, entre el 1 de noviembre de 2014 y el 31 de marzo de 2017, si un Estado lo solicita, se podrá utilizar el sistema tradicional de voto ponderado para obtener la mayoría cualificada. ${ }^{39}$

39 Vid. Art. 3 del Protocolo no 36 sobre las disposiciones transitorias (DO C 115, 9.5.2008, p. $322)$. 
Por otra parte, y como producto de la exigencia de Polonia, se adoptó también un procedimiento de garantía para los Estados miembros — que cabría denominar, dado su contenido, como "Ioannina $I I$, por el cual, entre el 1 de noviembre de 2014 y el 31 de marzo de 2017, si un número de Estados que supusiese, al menos, las tres cuartas partes de la población, o un mínimo de las tres cuartas partes del número de Estados miembros, necesarios para constituir una minoría de bloqueo, manifestase su oposición a que el Consejo adoptase un acto por mayoría cualificada, el Consejo deberá debatir el asunto y hacer cuanto esté en sus manos para lograr, dentro de un plazo razonable, una solución satisfactoria. A partir del 1 de abril de 2017, no sólo se mantiene este procedimiento de excepción, sino que se reduce el número de Estados y la cantidad de población representada para poder activarlo. Así, a partir de esa fecha se exige un número de Estados que represente, al menos, el 55\% de la población, o, al menos, el 55\% del número de Estados miembros, necesarios para constituir una minoría de bloqueo. ${ }^{40}$

\section{- Cláusula de solidaridad}

El Tratado de Lisboa introduce una regulación muy extensa del principio de solidaridad. De forma específica, sin embargo, este principio va a ser regulado en los Tratados con una doble vertiente: $a$ ) la solidaridad en el supuesto de agresión armada, y b) la solidaridad en el supuesto de ataque terrorista o de catástrofe.

a) La cláusula de solidaridad en el supuesto de agresión armada está prevista en el Art. 42.7 del TUE, el cual obliga a los demás Estados miembros a prestar ayuda y asistencia, con todos los medios a su alcance, al Estado agredido. Ello se entiende de conformidad con el artículo 51 de la Carta de las Naciones Unidas y sin perjuicio del carácter específico de la política de seguridad y defensa de determinados Estados miembros, y de sus compromisos en el marco de la Organización del Tratado del Atlántico Norte.

b) La solidaridad en el supuesto de ataque terrorista o catástrofe, de origen natural o humano, está prevista en el Art. 222 del TFUE. En este caso, se establece que, para prestar su ayuda solidaria, los Estados miembros actuarán conjuntamente y se coordinarán en el seno del Consejo. En esta línea, se establece que la Unión movilizará todos los instrumentos de que disponga, incluidos los medios militares puestos a su disposición por los Estados miembros. Sin embargo, en la Declaración ( $n^{\circ}$ 37) relativa al artículo 222 del Tratado de Funcionamiento de la Unión Europea, se establece el derecho de los otros Estados miembros a escoger los medios que consideren más apropiados para cumplir con su obligación de solidaridad con respecto al Estado afectado.

40 Vid. Declaración $n^{\circ} 7$ relativa al apartado 4 del artículo 16 del Tratado de la Unión Europea y al apartado 2 del artículo 238 del Tratado de Funcionamiento de la Unión Europea (DO C $115,9.5 .2008$, p. 338). 
Por lo demás, la solidaridad aparece ahora explicitada también en otros ámbitos de los Tratados, por virtud del Tratado de Lisboa. Así, aparece regulada como un valor de la UE (Art 2 TUE); como una exigencia genérica de las relaciones entre los Estados miembros (Art 3 TUE); como un principio inspirador de las relaciones internacionales (Art. 21 TUE); en el ámbito de la política exterior (Arts. 24, 31 TUE); en el espacio de libertad, seguridad y justicia (Arts. 67.2, 80 TFUE); en la política económica (Art. 122.1 TFUE); en la política social (Protocolo $\mathrm{n}^{\circ} 28$ sobre la cohesión económica, social y territorial); y en el ámbito de la política energética de la UE (Arts. 194, 122 TFUE).

A mayor abundamiento, no puede olvidarse que, en términos genéricos, de acuerdo con el "principio de cooperación leal", la Unión y los Estados miembros tienen el deber de respetarse y asistirse mutuamente en el cumplimiento de las misiones que se derivan de los Tratados (Art. 4.3 TUE).

\section{- Cooperaciones reforzadas}

La reforma del Tratado de Lisboa no cambia de manera sustantiva la regulación de las cooperaciones reforzadas. Solo introduce pequeñas modificaciones en el sentido de facilitar el recurso a este instrumento de integración, al mismo tiempo que requiere la aprobación del Parlamento Europeo. Por otra parte, el Tratado de Lisboa exige ahora un mínimo de nueve Estados, para componer una cooperación reforzada, mientras que el Tratado constitucional exigía al menos un tercio de los Estados miembros (Art. I-44). El viejo TUE exigía un mínimo de ocho Estados (Arts. 40 A y 43).

En términos sistemáticos, las cooperaciones reforzadas aparecen reguladas, primero en el TUE, en lo que se refiere a sus aspectos básicos (Tit. IV, Art. 20), y luego en el TFUE, donde se detallan los aspectos específicos de su regulación (Tit. III de la Sexta Parte, Arts. 326-334). Además, una forma específica de cooperación reforzada, aplicable en el terreno de la cooperación policial y judicial, se prevé en los Arts. 82, 83, 86 y 87 TFUE.

\section{- Nuevas bases jurídicas}

El Tratado de Lisboa introduce también nuevas bases jurídicas en varios ámbitos, con nuevas o extendidas competencias atribuidas a la UE: la pesca, que es ahora mencionada y regulada de forma específica en el campo de la regulación de la "agricultura y pesca" (Tít. III de la Tercera Parte del TFUE) campo en el que el Parlamento Europeo pasa ahora a adquirir el papel de colegislador con el Consejo-, atribuyéndose a la Unión, además, la competencia exclusiva en la conservación de los recursos biológicos marinos (Art. 3 TFUE); los servicios de interés económico general (Arts. 14, 106 TFUE; incluida la formulación del Protocolo $\mathrm{n}^{\circ} 26$ sobre los servicios de interés general, que no recogía el Tratado constitucional); la protección de los derechos de propiedad intelectual e industrial (Art. 118 TFUE); el deporte (Art. 165 TFUE); la política espacial (Art. 189 TFUE); la política de medio ambiente, en 
la que se incluye como uno de los objetivos específicos, "el fomento de medidas a escala internacional destinadas a hacer frente a los problemas regionales o mundiales del medio ambiente" (Arts. 191-193 TFUE; también Art. 11 TFUE y Arts. 3.5, 21.2.f TUE); la energía (Art. 194 TFUE); el turismo (Art. 195 TFUE); la protección civil (Art. 196 TFUE); y la cooperación administrativa (Art. 197 TFUE).

\section{- Cláusulas horizontales}

Se precisan y se regulan ahora de manera sistemática y más extensa —en el Tit. II de la Primera Parte del TFUE - las denominadas cláusulas horizontales o transversales, que son, en realidad, exigencias comunes que deberán ser integradas o tenidas en cuenta en la definición y ejecución de todas las políticas y acciones de la UE. Así: la eliminación las desigualdades entre el hombre y la mujer y la promoción de su igualdad (Art. 8 TFUE); la promoción del empleo, la garantía de una protección social adecuada, la lucha contra la exclusión social, la promoción de la educación y la protección de la salud humana (Art. 9 TFUE); la lucha contra toda discriminación por razón de sexo, raza u origen étnico, religión o convicciones, discapacidad, edad u orientación sexual (Art. 10 TFUE); la protección del medio ambiente y el fomento de un desarrollo sostenible (Art. 11 TFUE); la protección de los consumidores (Art. 12 TFUE); y el bienestar de los animales como seres sensibles, "respetando al mismo tiempo las disposiciones legales o administrativas y las costumbres de los Estados miembros relativas, en particular, a ritos religiosos, tradiciones culturales y patrimonio regional" (Art. 13 TFUE).

\section{- Pertenencia a la UE}

En lo que se refiere al ingreso en la UE, el Tratado de Lisboa recoge las aportaciones de la Constitución europea referidas a la exigencia de que el Estado candidato respete los valores de la Unión, mencionados en el artículo 2 del TUE, y de que se comprometa a promoverlos; además de la notificación de la solicitud de adhesión a los Parlamentos nacionales de los Estados miembros. Se añade ahora, sin embargo, la exigencia de tener en cuenta también "los criterios de elegibilidad acordados por el Consejo Europeo". Referencia implícita que hace el Tratado de Lisboa a los denominados "criterios de Copenhague", adoptados por el Consejo Europeo de Copenhague, de 21-22 de junio de 1993, exigibles a todo Estado europeo que dese ingresar en la UE (Art. 49 TUE).

En sentido contrario, el Tratado de Lisboa introduce también un precepto - tomado al pié de la letra del Art. I-60 de la Constitución europea- por el cual se admite la posibilidad, no incluida previamente en los Tratados, de que un Estado miembro se retire voluntariamente de la UE (Art. 50 TUE). Lo característico de este procedimiento de salida de la UE es que el acuerdo de separación, que ha de concluir el Consejo con el Estado en cuestión, ha de ser aprobado por el Parlamento Europeo. 


\section{— Revisión de los Tratados}

Y, en fin, en lo que se refiere a la reforma de los Tratados, se introduce una nueva formulación del procedimiento de revisión, que distingue entre el "procedimiento de revisión ordinario" y los "procedimientos de revisión simplificados" (Art. 48 TUE).

El denominado procedimiento de revisión ordinario es el procedimiento de reforma de los Tratados, propiamente dicho. Lo característico de este procedimiento, en relación con la regulación anterior, es que se añade ahora la participación en el proceso de una Convención, compuesta por representantes del Parlamento Europeo, de los Parlamentos nacionales, de los Gobiernos de los Estados miembros y de la Comisión, la cual examinará los proyectos de revisión y adoptará por consenso una recomendación dirigida a la CIG. Se incluye ahora también la exigencia de notificación a los Parlamentos nacionales de los Estados miembros de todo proyecto de reforma de los Tratados, al inicio del proceso (apartados 2 a 5 del Art. 48 TUE). La Convención que ahora prevé el Art. 48.3 del TUE se basa en el modelo y en la experiencia exitosa de las convenciones utilizadas para la redacción de la Carta de los Derechos Fundamentales de la UE (1999-2000) y para la redacción de la Constitución Europea (2002-2003).

Los denominados "procedimientos de revisión simplificados" incluyen, en realidad, dos cosas bien diferentes: a) por un lado, un procedimiento simplificado de reforma, para modificar la Parte Tercera del TFUE ("Políticas y acciones internas de la Unión"), que autoriza al Consejo Europeo a adoptar por unanimidad las decisiones correspondientes de reforma, a iniciativa de cualquier Estado miembro, del Parlamento Europeo, o de la Comisión (apartado 6 del Art. 48 TUE). No se necesita aquí, pues, el largo y complejo proceso ordinario de reforma. Y b) por otro lado, dos procedimientos que - en términos técnicos- cabría conceptuar más bien como excepciones constitucionales o, incluso, como formas de mutación constitucional, y no propiamente como un procedimiento de revisión (apartado 7 del Art. 48 TUE).

Se trata en este último supuesto de lo que en la jerga comunitaria se denominan "cláusulas pasarela", establecidas durante la elaboración de la frustrada Constitución europea para satisfacer, tanto a quienes pretendían la generalización de la decisión por mayoría cualificada, como a quienes, por el contrario, pretendían mantener una amplia reserva para la unanimidad. Sobre la convocatoria y compomaón de la Convención de la Carta de los Derechos Fundamentales de la UE, vid. Consejo Europeo de Colonia, Conclusiones de la Presidencia, Colonia, 3-4 de junio de 1999 (SN 150/1/99 REV 1 ES), Anexo IV: Decisión del Consejo Europeo relativa a la elaboración de una carta de derechos fundamentales de la Unión Europea, pág. 43; y Consejo Europeo de Tampere, Conclusiones de la Presidencia Tampere, 15-16 de octubre de 1999, Anexo: Composición, método de trabajo y disposiciones prácticas del órgano competente para la elaboración de un proyecto de carta de los derechos fundamentales de la Unión Europea, con arreglo a lo dispuesto en las conclusio- 
nes de Colonia. Sobre la convocatoria y composición de la Convención de la Constitución europea, vid. Consejo Europeo de Colonia. Así, la primera de estas cláusulas supone que, cuando los Tratados exijan que el Consejo se pronuncie por unanimidad en un ámbito o en un caso determinado, el Consejo Europeo podrá adoptar por unanimidad una decisión por la que se autorice al Consejo a pronunciarse por mayoría cualificada. ${ }^{41} \mathrm{Y}$ la segunda supone que, cuando los Tratados exijan que el Consejo adopte actos legislativos con arreglo a un procedimiento legislativo especial, el Consejo Europeo podrá adoptar por unanimidad una decisión por la que le autorice a adoptar dichos actos con arreglo al procedimiento legislativo ordinario. ${ }^{42}$ En todo caso, se requiere que toda iniciativa presentada en el Consejo Europeo a este respecto sea transmitida a los Parlamentos nacionales, los cuales - cualquiera de ellos, individualmente - pueden bloquear este procedimiento, manifestando su oposición al mismo en un plazo de seis meses a partir de su notificación. Además, la decisión del Consejo Europeo requiere también la previa aprobación del Parlamento Europeo, adoptada por la mayoría de sus miembros (apartado 7 del Art. 48 TUE). Con todo lo cual, la aparente flexibilización del proceso decisorio que las "cláusulas pasarela" suponen, es muy frágil o limitada y queda pendiente - entre otras cosas- de la decisión que pueda adoptar al respecto cualquier Parlamento nacional, por muy pequeño o poco representativo que éste sea.

Por otra parte, se introduce la previsión - que no incluía el Tratado constitucional - por la cual los proyectos de revisión de los Tratados podrán tener por finalidad, entre otras cosas, "la de aumentar o reducir las competencias atribuidas a la Unión en los Tratados" (Art. 48.2 del TUE y Declaración $\mathrm{n}^{\circ} 18$ relativa a la delimitación de las competencias).

Esta última previsión formal, junto con el reconocimiento de la posibilidad de la retirada de la Unión por parte de un Estado miembro, rompen, por primera vez en más de cincuenta años, con la concepción filosófica y la lógica que inspiró el proceso de integración europea desde sus inicios, cuya dinámica —basada en la intención de los fundadores de las Comunidades Europeas, en las previsiones mismas de los Tratados y en la jurisprudencia del Tribunal de Justicia - había seguido hasta ahora una línea expansiva y de acentuación del proceso, que logró poner a la UE en la posición que hoy ocupa en el contexto continental y mundial. Es evidente, pues, que los sectores más reacios a la integración política de Europa, han logrado dejar su huella en los Tratados y, quizá también — siquiera temporalmente-, frenar el impulso de este proceso.

41 En el mismo sentido: Art. 31.3 TUE, referido a la PESC, y Art. 312.2 del TFUE, referido al marco financiero plurianual de la UE.

42 El Art. 333 del TFUE establece una "cláusula pasarela" peculiar, en el ámbito de las cooperaciones reforzadas, que permite al propio Consejo adoptar por sí mismo, por unanimidad, la decisión de pronunciarse por mayoría cualificada y de utilizar el procedimiento legislativo ordinario, cuando el Tratado exija unanimidad o un procedimiento legislativo especial. 


\section{CONCLUSIÓN}

El Tratado de Lisboa supone la reforma más importante realizada en el seno de la Unión Europea desde su misma creación. Las modificaciones realizadas son verdaderamente sustanciales y han afectado a la estructura constitucional básica de la Unión, a su composición, a su estructura institucional, a su ordenamiento jurídico y a su sistema de competencias. En este sentido, si bien es verdad que el Tratado de Lisboa es el resultado del fracaso de la Constitución europea y, por lo tanto, supone un paso atrás con respecto a los aspectos simbólicos y formales - la ordenación, la claridad, la simplificación- que ésta aportaba, es igualmente cierto que el grueso de las aportaciones materiales de la Constitución europea han sido recogidas por el Tratado de Lisboa y, por lo tanto, son hoy ya parte de esa nueva estructura constitucional de la reformada UE.

Por otra parte, si bien es verdad que estas reformas suponen un avance en el proceso de integración política de la UE, es igualmente cierto que estas reformas llevan detrás de sí el intento de congelar ese proceso de integración, impidiendo que siga avanzando y, lo que es peor, abriendo la puerta a su retroceso, gracias a la posibilidad ahora establecida de reformar los Tratados para reducir las competencias de la Unión e, incluso, de salirse de su seno.

La reforma del Tratado de Lisboa, como el dios Jano, tiene, pues, dos caras, una positiva y otra negativa, una mirando hacia detrás y otra mirando hacia delante. Y, de la misma manera, se puede decir que hoy conviven en el seno de la Unión también dos filosofías cuyas fuerzas - sobre todo, tras la última ampliación de la UE- se encuentran muy equilibradas y que determinan el carácter de su gobierno y su propio avance histórico: la concepción de quienes ven en la Unión un proceso inacabado de integración política, para los cuales la reforma de Lisboa es sólo una fase más en este proceso, y la de quienes ven en esta reforma el cierre definitivo de un proceso, que no permite ir ya más adelante, dado que ello supondría el desustanciamiento definitivo de los Estados nacionales que son el sostén de la Unión.

Es claro que, a corto plazo, no es previsible que se vayan a producir más cambios sustanciales de la naturaleza de los ahora realizados y, por lo tanto, la Unión permanecerá congelada en su actual estructura por un cierto tiempo - con excepción de las futuras ampliaciones que, en realidad, están ya programadas.

Pero, por otro lado, es muy difícil poder asegurar que un proceso político de tan larga trayectoria se vaya a frenar de manera definitiva y no mantenga su propia dinámica interna, engendrada, incluso, con anterioridad a la creación de las Comunidades Europeas, y que le ha hecho superar ya grandes obstáculos en otras etapas de su historia. La evolución en esta línea es, por tanto, previsible, siquiera sea a largo plazo. Y ello, después de todo, lo reconoce el propio Tratado de la Unión Europea, cuando establece en su Art. 1 


\section{que éste "constituye una nueva etapa en el proceso creador de una unión cada vez más estrecha entre los pueblos de Europa".}

TiTLE: The new Constitution of the European Union: The Treaty of Lisbon and the reform of the Constitutive Treaties.

ABSTRACT: The ratification of the Lisbon Traty - in force since December 1, 2009- means the overcoming of one of the longest and tensest stages of the history of the European Union. A stage that characterized by the emergence of great expectations concerning the change in the constitutional structure and the substantial content of the EU and by the frustration of these expectations mirrored in the failure the European Constitution. The result of this long process is the Treaty of Lisbon which reforms the old Treaties in force up until now and establishes a new constitutional structure in the Union, with a new substantial content. A reform that tries to overcome also the problems that the EU faced then, but also the new problems and challenges that the EU has to face now and in the future. This papar tries to make also a detailed analysis of this new constitutional structure and the reforms that the Treaty of Lisbon has broughAt with itself.

Resumen: La entrada en vigor, el 1 de diciembre de 2009, del Tratado de Lisboa ha supuesto la superación de una de las etapas más largas y tensas de la historia de la Unión Europea. Una etapa que estuvo caracterizada por el surgimiento de grandes expectativas con respecto al cambio en la estructura y en los contenidos sustantivos de la UE y por el frustrante fracaso de las mismas que queda reflejado en el fracaso mismo de la Constitución europea. El resultado de este proceso ha sido la formulación de un nuevo Tratado - el Tratado de Lisboa- que viene a reformar los viejos Tratados hasta ahora vigentes y a establecer una nueva estructura constitucional en la Unión, con nuevos contenidos materiales, que tratan de superar lo problemas que afectaban a la UE entonces, pero también los nuevos problemas y desafios que afronta la UE el presente. Este trabajo, pues, trata de analizar en detalle esa nueva estructura constitucional y las reformas aportadas por el Tratado de Lisboa.

KEYWORDS: Treaty of Lisbon. European Union. European constitution. Constitutional structure of the Union. Reform of the EU.

Palabras clave: Tratado de Lisboa. Unión Europea. Constitución europea. Estructura constitucional de la Unión. Reforma de la UE. 